\title{
Influence of Lane-Changing Behavior on Traffic Flow Velocity in Mixed Traffic Environment
}

\author{
Han Xie $\mathbb{D}^{D}$, Qinghua Ren $(\mathbb{D}$, and Zheng Lei $(\mathbb{D}$ \\ Xihua University, School of Management, Jinniu, Chengdu, China \\ Correspondence should be addressed to Qinghua Ren; ren-qinghua@163.com
}

Received 4 November 2021; Revised 7 December 2021; Accepted 11 December 2021; Published 18 January 2022

Academic Editor: Zhihong Yao

Copyright (c) 2022 Han Xie et al. This is an open access article distributed under the Creative Commons Attribution License, which permits unrestricted use, distribution, and reproduction in any medium, provided the original work is properly cited.

\begin{abstract}
In mixed traffic with autonomous vehicles, the relationship between speed and lane-changing behavior is an important basis for mixed traffic control. In this study, we use empirical, simulation, and data-driven methods to study the relationship between speed and lane change rates in mixed traffic under different autonomous vehicle penetration rates. We use the empirical data to establish the corresponding road simulation models. Based on the simulation model, the traffic flow simulation experiments under the conditions of $10 \%, 20 \%, 30 \%, 40 \%, 50 \%, 60 \%, 70 \%, 80 \%$, and $90 \%$ penetration rate of autonomous vehicles were carried out. The analysis of the simulation results found that: (1) the penetration of autonomous vehicles into the road has a positive impact on the lanes far away from the entrance and exit, while the impact on the lanes closer to the entrance and exit is not obvious. (2) Lanechanging behavior has effectively decreased with the penetration of autonomous vehicles, but it is not obvious when the penetration rate exceeds $10 \%$, and there is no significant drop in the lane connecting the entrance and exit. (3) There is a linear relationship between speed and lane-changing rate. Under different penetration rates, the data-driven analysis is used to perform multiple linear regressions, and the regression formula fits are all above 0.7. Based on the above findings, the linear formula of the fitting is proposed, and the value interval of the parameters in different states is given as well. Due to the small changes in the parameter values under different permeability conditions, the model has a certain degree of stability. The speed-lane change rate model proposed in this study can better describe the relationship between the speed of the ring-shaped urban expressway and the lane-changing behavior in the mixed traffic environment with the larger traffic flow.
\end{abstract}

\section{Introduction}

In recent years, with the development of autonomous driving technology, autonomous vehicles will appear on urban roads in the future. Related researchers predict that by 2040 , as many as $75 \%$ of vehicles may be self-driving (IEEE Press Release, 2012). Mixed driving of autonomous vehicles and manually driven vehicles will be the normal state of traffic for a long time in the future. Due to the mixing of autonomous vehicles, the traffic state is not the same as that under manual driving. It is important to the management and control of mixed traffic by understanding the operation mechanism of mixed traffic in the future.

Speed, as one of the important parameters that describes the characteristics of traffic flow, has great significance to the description of the state of traffic flow. Lane-changing behavior, as one of the basic behaviors of vehicles running on the road, has a great disturbance to traffic flow and is also one of the main reasons for traffic congestion. In the case of small traffic flow, the behavior of changing lanes has little interference with the speed, but in the case of large traffic flow, this interference is more obvious.

A self-driving vehicle is a vehicle that can automatically drive on the road in a controlled environment. This vehicle will automatically choose to follow the car when the traffic does not allow it to change lanes. But, under special circumstances (such as obstacles ahead, the target lane can only be reached after changing lanes, and a more suitable lane needs to be selected), the lane change behavior will be performed. In mixed traffic, autonomous vehicles will affect speed and will also effectively reduce the occurrence of lanechanging behavior [1-5]. It is important to understand the 
impact of autonomous vehicles on the speed and lanechanging behavior in a 4-lane closed road in mixed traffic. The affection is very important to understand the operating mechanism of traffic flow in mixed traffic. The current research studies on the lane-changing behavior of autonomous vehicles are mainly focused on the lane-changing behavior of a single autonomous vehicle. Research methods mainly used data-driven model [6-8] and simulation model. There are few studies on the impact of lane-changing behavior on traffic flow, especially in each lane. For traffic flow, lanechanging behavior has a greater impact on each lane than on a road section. Therefore, it has great significance to study the relationship between speed and lane-changing behavior in each lane. The relationship is important to understand the operation mechanism of traffic flow in mixed traffic in the urban road with closed loops, multiple lanes, and multiple entrances and has practical significance for future traffic control under mixed traffic conditions.

Through the current studies, we found that speed is a very important parameter to describe the traffic flow state. Most research studies on speed are based on basic graph theory. Basic graph theory is the basis of traffic flow under manual driving. For mixed traffic, some scholars had proposed a basic graph. The basic graph of mixed traffic mainly studied the capability, that is, the relationship between flow and density within nonfull density [9-13]. The current studies are mainly from two aspects. On the one hand, the data of flow and density are obtained through simulation, and the relationship graph of flow and density is fitted $[14,15]$. On the other hand, the relationship graph of flow, density, and speed is obtained from the average head-tohead distance of mixed traffic in a balanced state by theoretical analysis methods [16-21]. In the research studies of the basic graph of mixed traffic, the main studies are focused on the impact of car-following behavior on the three basic parameters of traffic flow. The important perspective is focus on car-following behavior. However, there are not only carfollowing behavior and lane-changing behavior of autonomous vehicles in mixed traffic but also lane-changing behavior of human-driven vehicles. But the study of lanechanging behavior is not involved in the basic graph of mixed traffic. At the same time, the research studies on speed are only from the three basic parameters of traffic flow and the car-following model of auto-driving vehicles, while the relationship between speed and lane-changing behavior in mixed traffic has not been studied.

The main research studies on the impact of lane-changing behavior on traffic flow under human driving are considered from the traffic flow model. Based on the classic LWR model, Laval and Daganzo [22] proposed a modified model [23, 24] and further proposed a model that used four parameters of speed, speed, capacity, and lane change rate [24]. In the model, lane-changing vehicles are described as particles that completely blocked the traffic flow in each lane. Jin [25] clearly proposed that lane-changing behavior had an impact on traffic capacity, but it still used the LWR model and introduced lane-changing factor to modify the three parameters of traffic flow, density, and speed. In HCM2010 [26], specific calculation methods for interwoven and non-interwoven lanes are given for the interweaving area of expressways. The lane-changing rate is introduced for interwoven lanes, but the relationship between lane-changing behavior and speed is not analyzed. The above studies are all within the basic graph of manual driving vehicles, and none of them analyzes the relationship between speed and lane-changing behavior. Park and Rictchie [27] studied the relationship between lanechanging behavior and speed. The study proposed a regression model on the measured data of lane-changing behavior, vehicle types, the difference between upstream and downstream traffic flow, and speed, respectively, to study the influence of lane-changing behavior, vehicle types, and the difference between upstream and downstream traffic flow on speed in the detection area. The lane-changing behavior is defined as the number of lane-changing behaviors performed by a single vehicle in the detection interval, and the different lane-changing times are counted to establish a multiple regression model. The model shows that lane-changing behavior can affect speed changes more than factors such as vehicle type and the differences between upstream and downstream traffic flow. Park and Rictchie gave a multiple linear regression model, as shown in [27]

$v=6.169-4.410 L 0+5.154 L 2+11.090 L 3+44.150 L 4$.

In the equation, $v$ is the average speed in the measurement section; $L 0$ is the total number of vehicles, in which lane changes are 0 time in the measurement section per unit time/the total number of vehicles in the measurement section per unit time; $L 2$ is the total number of vehicles, in which lane changes are 2 times in the measurement section per unit time/the total number of vehicles in the measurement section per unit time; L3 is the total number of vehicles, in which lane changes are 3 times in the measurement section per unit time/the total number of vehicles in the measurement section per unit time; and L4 is the total number of vehicles, in which lane changes are greater than or equal to 4 times in the measurement section per unit time/ the total number of vehicles in the measurement section per unit time.

A simulation model was used to study the relationship between speed and lane-changing behavior through each vehicle trajectory in the measurement section from the microscopic view. However, this study has not been conducted on the affect of lane-changing behavior on each lane. The behavior of changing lanes has a greater impact on each lane, but the impact on the entire road is not as great as that in each lane. Moreover, in low traffic flow, the lane-changing behavior of a single vehicle has a minor impact on the road. But in large traffic flow, the impact of lane-changing behavior is more prominent. Therefore, it is more important to study the influence of lane-changing behavior in each lane under large traffic flow, especially speed. The above studies are all carried out in a human-driving environment.

In the autonomous driving environment, the study of lane-changing behavior mainly focuses on behavior prediction [28-30] and lane-changing behavior [31, 32]. Liu et al. [33] used a dynamic control model to describe the lanechanging motivation at high speed. The motive of changing 
lanes was considered from both horizontal and vertical aspects, using speed as the motive for safety guarantee, and predicting the behavior of lane changing. Zheng et al. [34] also adopted lane-changing motivation models from horizontal and vertical aspects in a dynamic driving environment. The model used speed, acceleration, and ending time as inputs in the longitudinal direction and used trajectories as inputs in the vertical direction to make decisions about lane-changing behavior. Of course, it is not enough to make lane-changing decision from the intention. Decision also need to consider collisions [35], front and rear cars [36, 37], current road condition $[38,39]$, and other aspects. In addition, Jongsang et al. [35] used a deep auto-encoding network to establish a multivariate model for lane-changing decisions. Most studies are based on human behavior, and most models are similar to human behavior models. Compared with human behavior models, autonomous vehicle models used more and more accurate information when making decisions. When an autonomous vehicle enters mixed traffic, it will be naturally affected by humandriving vehicles, and there are more factors to be considered when changing lanes. However, the current research studies are mostly based on the auto-driving vehicle, and the research studies in the mixed traffic are mostly from the road section and rarely considered from each lane. For multilane road, the impact of lane-changing behavior on each lane is greater than the impact on the entire road or the section. In this study, the influence of lane-changing behavior of each lane on speed is studied. At the same time, speed is an important parameter to measure the traffic state. It is important to understand the relationship between speed and lane-changing behavior in mixed traffic in each lane. The relationship is important for understanding the operating mechanism of mixed traffic flow.

In summary, the current research studies are less involved in the impact of lane-changing behavior on traffic flow in mixed traffic. The research studies on the relationship between lane-changing behavior and speed are mainly from the human-driving environment and mainly involved the trajectory of lane-changing vehicles and from the road section. The research on the relationship between lanechanging behavior and speed from each lane is rarely involved. The behavior of changing lanes has a great impact on speed in each lane, especially in heavy traffic. Therefore, it is necessary to study the relationship between speed and lanechanging behavior in each lane on closed city roads with circular multilane under heavy traffic flow in mixed traffic. This study uses empirical, simulation, and data-driven research methods to study the relationship between lanechanging behavior and speed in each lane based on the different penetration rates of autonomous vehicles. The research conducted an empirical study on the third ring expressway in Chengdu, China, which has the characteristics of a typical ring-shaped urban expressway [40]. We collected relevant data and established a corresponding simulation model. The relationships between speed and lane-changing behavior, under the autonomous vehicle penetration rates of $10 \%, 20 \%, 30 \%, 40 \%, 50 \%, 60 \%, 70 \%, 80 \%$, and $90 \%$, are studied through simulation models. A data-driven modeling method was used to establish a linear regression model. For the first time, we proposed a single-lane speed and lane change rate model for the closed-loop multilane urban road under mixed traffic environment and have given the corresponding value interval of the parameters. The model can better describe the relationship between the speed and the lane-changing behavior of a circular urban expressway in mixed traffic environment under the large traffic flow.

This study introduces the research background in the first part. The second part introduces the method we used. In this part, we introduce the verification of empirical research, the verification of simulation models, the simulation experiments, and the results obtained from the experiments. The third part is the results and discussion. In this part, the results of the analysis were obtained from the previous experiments, and the speed and lane change models were established. The last part is the conclusion.

\section{Method}

This study uses empirical, simulation, and data-driven methods to study the relationship between speed and lanechanging behavior. First, empirical methods were used to obtain data for simulation modeling. Then, we verified the accuracy and validity of the data. Finally, simulation and data-driven methods were used to analyze the data characteristics. The validity of the model is verified.

2.1. Empirical Verification. The data used in this study are video data, which were taken in 2011, 2015, and 2018. The videos came from on-site shooting and Chengdu Transportation Administration. We used manual method and self-made traffic flow recognition software to directly obtain the data from the videos. Collection points are shown in Figure 1.

In Figure 1, the points represent each selected collection point. The size of the points represents the number of data, which were collected in each collection point. The collection point satisfies the conditions of the section, which has entrances or exits, pedestrian overpasses, commercial and residential land usage on both sides of road, and the different road types. According to the statistics, the eligible sections on the third ring road can be classified into 4 types, namely, entrances or exits connected to the straight section and connected to overpasses, entrances or exits connected to curved section and connected to overpasses, entrances or exits connected to the straight section and not connected to overpasses, and entrances or exits connected to bends and not connected to overpasses, as shown in Figure 2.

There are four types, and at least one point of each type should be selected as the collection point. The nine points are used as the collection points in this study. The three parameters of the speed, the number of vehicles that changes into lane, and the number of vehicles that changes out of lane are collected from the videos. The collection time is the time period in the morning and afternoon of the working day with a large traffic flow. The collection situations are shown in Table 1. 


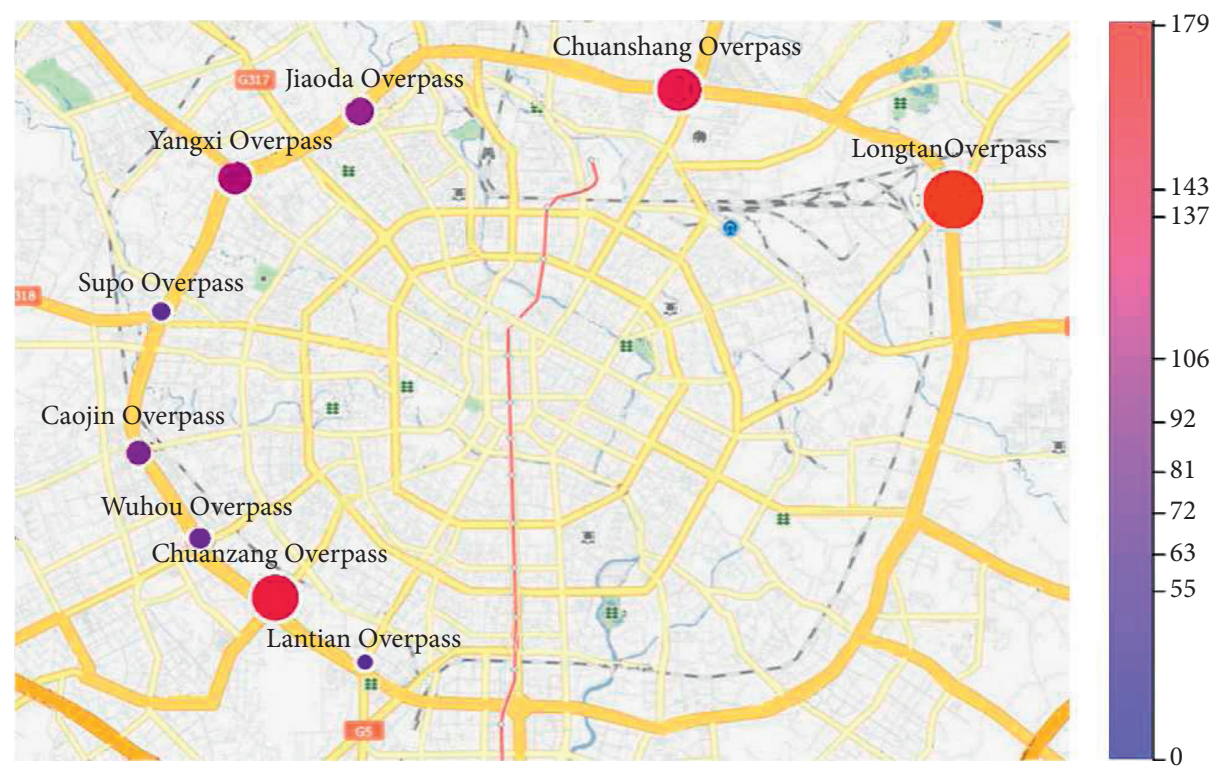

FIGURE 1: Collection point situation.

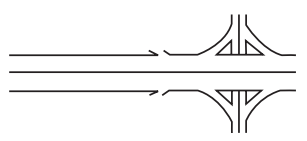

(a)

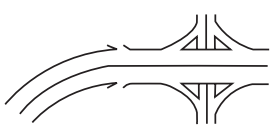

(b)

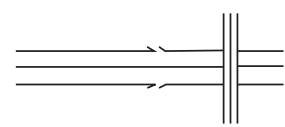

(c)

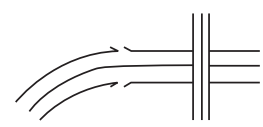

(d)

Figure 2: The sketches of connection and linear section. (a) The sketch of the connecting overpass and straight linear section. (b) The sketch of connecting overpass and bend linear section. (c) The sketch of connecting straight linear section. (d) The sketch of connecting bend linear section.

TABLE 1: Introduction of each collection location.

\begin{tabular}{|c|c|c|c|c|c|c|c|c|}
\hline \multirow{2}{*}{ Collection location } & \multirow{2}{*}{ Location } & \multirow{2}{*}{$\begin{array}{l}\text { Overpass } \\
\text { mode }\end{array}$} & \multicolumn{2}{|c|}{ Connecting road } & \multirow{2}{*}{$\begin{array}{l}\text { Date of data } \\
\text { acquisition }\end{array}$} & \multirow{2}{*}{$\begin{array}{c}\text { Time } \\
\text { (minutes) }\end{array}$} & \multirow{2}{*}{$\begin{array}{c}\text { Detection } \\
\text { distance } \\
\text { (meters) }\end{array}$} & \multirow{2}{*}{ Dataset } \\
\hline & & & Inner ring & Outer ring & & & & \\
\hline $\begin{array}{l}\text { Location } 1 \\
\text { (Sichuan-Shaanxi } \\
\text { overpass) }\end{array}$ & Northeast & Compound & $\begin{array}{l}\text { Zhaojue } \\
\text { temple south } \\
\text { road }\end{array}$ & $\begin{array}{l}\text { Rongdu } \\
\text { Avenue }\end{array}$ & $\begin{array}{l}2011-1-11 \\
2011-1-12\end{array}$ & 740 & 100 & 137 \\
\hline $\begin{array}{l}\text { Location } 2 \text { (Jiaoda } \\
\text { overpass) }\end{array}$ & Northwest & Compound & $\begin{array}{l}\text { Jiao Tong } \\
\text { University } \\
\text { road }\end{array}$ & $\begin{array}{l}\text { Xihua } \\
\text { Avenue }\end{array}$ & $\begin{array}{c}2010-5-27 \\
2015-7-21 \\
2011-1-5 \\
2011-1-11 \\
2011-1-12\end{array}$ & 455 & 200 & 92 \\
\hline $\begin{array}{l}\text { Location } 3 \text { (Yangxi } \\
\text { overpass) }\end{array}$ & Northwest & Compound & Shuhan road & $\begin{array}{c}\text { Shuhan } \\
\text { West road }\end{array}$ & $\begin{array}{l}2011-1-11 \\
2011-1-12\end{array}$ & 600 & 100 & 106 \\
\hline $\begin{array}{l}\text { Location } 4 \text { (Supo } \\
\text { overpass) }\end{array}$ & West & Compound & $\begin{array}{l}\text { Su Po West } \\
\text { road }\end{array}$ & $\begin{array}{l}\text { Su Po West } \\
\text { road }\end{array}$ & $\begin{array}{l}2015-7-19 \\
2015-7-20 \\
2015-7-27\end{array}$ & 525 & 100 & 63 \\
\hline $\begin{array}{l}\text { Location } 5 \text { (Caojin } \\
\text { overpass) }\end{array}$ & West & Compound & Jinyang road & $\begin{array}{l}\text { Yongkang } \\
\text { road }\end{array}$ & $\begin{array}{l}2011-1-12 \\
2011-1-13\end{array}$ & 420 & 100 & 81 \\
\hline $\begin{array}{l}\text { Location } 6 \text { (Wuhou } \\
\text { overpass) }\end{array}$ & $\begin{array}{l}\text { South } \\
\text { west }\end{array}$ & Interchange & $\begin{array}{l}\text { Wuhou } \\
\text { Avenue }\end{array}$ & $\begin{array}{l}\text { Wuhou } \\
\text { Avenue }\end{array}$ & $\begin{array}{l}2011-1-12 \\
2011-1-13\end{array}$ & 610 & 100 & 72 \\
\hline $\begin{array}{l}\text { Location } \\
7 \text { (Sichuan-Tibet } \\
\text { overpass) }\end{array}$ & Southwest & Compound & Jialing road & $\begin{array}{l}\text { Twin } \\
\text { Avenue }\end{array}$ & $\begin{array}{l}2011-1-13 \\
2011-1-18\end{array}$ & 710 & 200 & 143 \\
\hline $\begin{array}{l}\text { Location } 8 \text { (Lantian } \\
\text { overpass) }\end{array}$ & Southwest & Compound & $\begin{array}{c}\text { Airport } \\
\text { expressway }\end{array}$ & $\begin{array}{c}\text { Airport } \\
\text { expressway }\end{array}$ & $\begin{array}{l}2015-7-19 \\
2015-7-20 \\
2015-7-27\end{array}$ & 525 & 100 & 55 \\
\hline $\begin{array}{l}\text { Location } 9 \text { (Fenghuang } \\
\text { overpass) }\end{array}$ & Northeast & Compound & Shili shop road & $\begin{array}{l}\text { Chenghua } \\
\text { Avenue }\end{array}$ & $\begin{array}{l}2015-7-10 \\
2018-7-11 \\
2018-7-12\end{array}$ & 1170 & 100 & 179 \\
\hline
\end{tabular}


In order to describe the road characteristics, the minimum sample size of statistics is adopted. Equation (2) [41] was used.

$$
n \geq\left(\frac{\sigma \bullet K}{E}\right)^{2}
$$

In the equation, $n$ is the minimum sample size for observation; $\sigma$ is the standard deviation of the sample of the observed speed; $K$ is the constant of confidence to meet expectations; and $E$ is the allowable error of speed. It depends on the accuracy of the mean speed, generally $1.5 \sim 2 \mathrm{~km} / \mathrm{h}$.

We used $\sigma=7 \mathrm{~km} / \mathrm{h}$ (according to the two-way eightlane road), $K=1.96$ (95\%), and $E=2 \mathrm{~km} / \mathrm{h}$. Then, we got the minimum sample size as 48 . That is to say, if the data groups collected are greater than 48 groups, the data can be used to describe the road section characteristics.

Comparing the videos, the unreasonable data were excluded, and the groups of available data were from 55 groups to 179 groups in each collection point. In this study, we studied three parameters: speed, the number of vehicles that changes into lanes, and the number of vehicles that changes out of lanes.

The speed $v$ describes the distance the vehicle passes in a unit of time. In traffic flow theory, speed is classified into 4 types: point speed, travel speed, design speed, and running speed. The average speed of the collected section is used in this study. At first, we used the travel speed to describe the speed of a single vehicle. The travel speed is calculated by [41]

$$
v=\frac{L \times 3600}{t \times 1000} \text {. }
$$

In the equation, $v$ is the travel speed in each lane $(\mathrm{km} / \mathrm{h})$; $L$ is the distance of the detection section (m); and $t$ is the travel time (h).

Then, the average speed of the collected section in each lane in the collection time interval is calculated by [41]

$$
\overline{V_{s}}=\frac{1}{1 / n \sum_{i=0}^{n} 1 / v_{i}} .
$$

In the equation, $\left(\overline{V_{s}}\right)$ is the average speed of the detection lane in the detection section $(\mathrm{km} / \mathrm{h}) ; n$ is the number of vehicles passing through the detection lane; and $v_{i}$ is the speed of the $i$-th vehicle passing through the detection lane $(\mathrm{km} / \mathrm{h})$.

The speed unit is $\mathrm{km} / \mathrm{h}$. In this study, the collection time interval was 5 minutes, and the data from each lane in the selected section were collected. In our software, if over half part of the vehicle is in the tested lane, then the data of this vehicle are calculated in the tested lane.

Lane change in or lane change out behavior refers to the behavior of vehicles entering the tested lane from other lanes or entering other lanes from the tested lane while running on the road, as shown in Figure 3.

In Figure 3, the blue vehicle is the vehicle to be changed in lanes, and it is planned to change to the target lane from the original driving lane. When the lane change happens, there are two states of the vehicle to the target lane, such as partial entry state and complete entry state. In this study, the behavior of changing into lanes in the target lane is

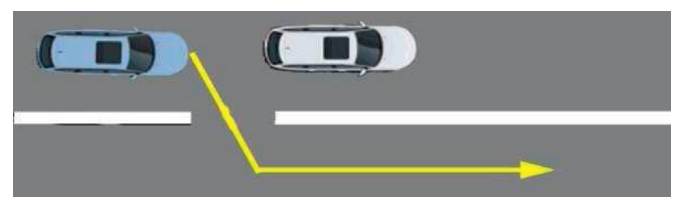

Figure 3: Schematic diagram of vehicle changing lanes (picture from the internet).

calculated in $>50 \%$ of the part of the vehicle in the target lane. The behavior of changing out of lanes is similar to the behavior of changing into lanes, except that the calculation is for vehicles leaving the tested lane.

The number of vehicles changing into the tested lane is also called the rate of changing into lanes, which refers to the number of vehicles entering the tested lane from other lanes within a unit time and unit length. The number of vehicles changing out of the tested lane is also called the rate of changing out of lanes, which refers to the number of vehicles entering other lanes from the tested lane in a unit time and unit length. Here, the unit time is $1 \mathrm{~h}$, and the unit length is $1 \mathrm{~km}$. It is consistent with the definition of lane change in and change out in HCM2010 [26]. However, HCM2010 [26] did not study lane-changing behavior of vehicles in the section between the entrance ramp and exit ramp. On the highway, the distance between the entrance ramp and exit ramp is generally long, and the impact area of the vehicles, which came from the entrance ramp or exit ramp, is relatively minor. On the urban expressway, the distance between the on-ramp and off-ramp is relatively short, and almost the entire road is in the weaving area, and the impact of changing lanes in the road is greater. If we only considered the impact of the lane-changing behavior on the entrance ramp and exit ramp without the section between the on-ramp and off-ramp, we cannot accurately describe the impact of lane-changing behavior on the urban expressway.

In the data collection, the collection time interval is $5 \mathrm{~min}$, and the distance of each section is $100 \mathrm{~m}$ or $200 \mathrm{~m}$. Before data analysis, the data were standardized and converted, the final time interval was $1 \mathrm{~h}$, and the length was $1 \mathrm{~km}$. The unit of the rate of changing into lanes and the rate of changing out of lanes are times that are as same as the number of lane changes in HCM2010 [26]. The data are represented by LCi and LCo, respectively.

In the data arrangement, we found that some data were missing. This situation happens because of the discontinuity of the collection locations and time. We used the time difference method to complement the data, as shown in Equation (5). [41]. After completion, the data are 923 groups. The histograms of the data are shown in Figure 4.

$$
Z^{t}\left(t_{j}, x_{i}\right)= \begin{cases}\left(t_{a}, x_{i}\right), & t_{j}=t_{1}, \\ z\left(t_{j-1}, x_{i}\right)+\frac{\Delta t}{t_{j-1}-t_{a}} z\left(t_{a}, x_{i}\right), & t_{1}<t_{j}<t_{p}, \\ z\left(t_{j}, x_{i-1}\right), & t_{j}=t_{p} .\end{cases}
$$



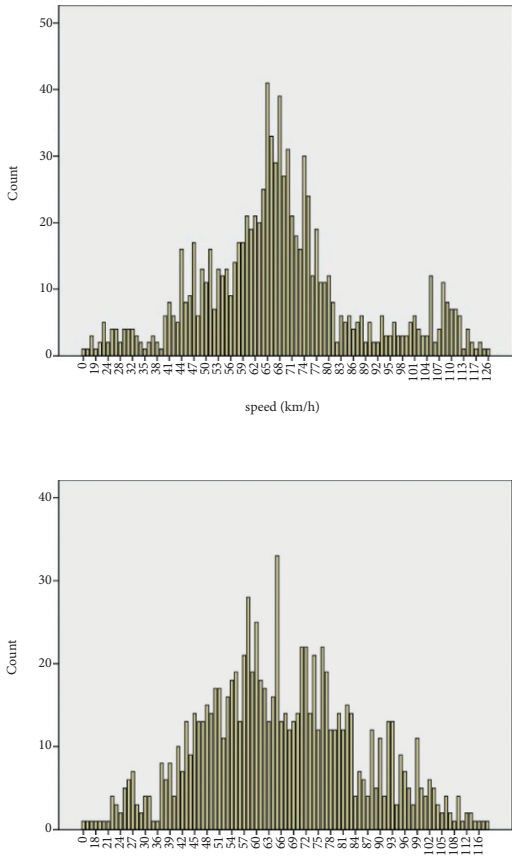

speed $(\mathrm{km} / \mathrm{h})$

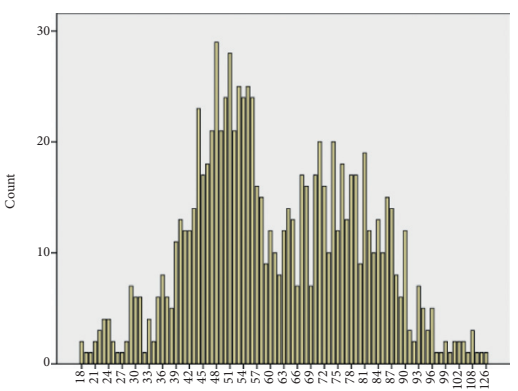

speed $(\mathrm{km} / \mathrm{h})$

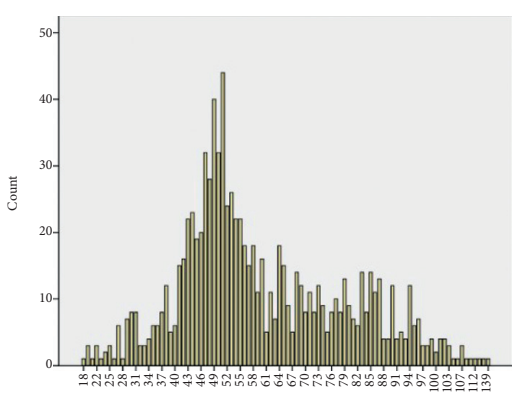

$\operatorname{speed}(\mathrm{km} / \mathrm{h})$

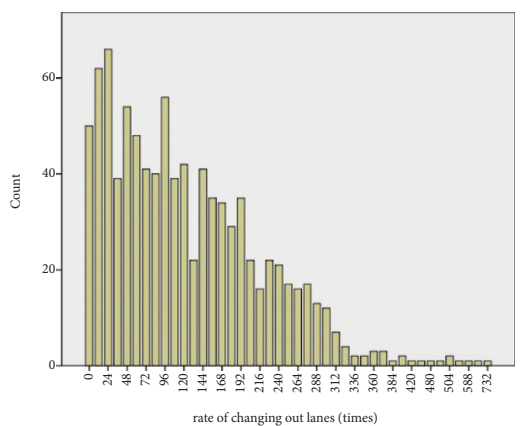

(a)

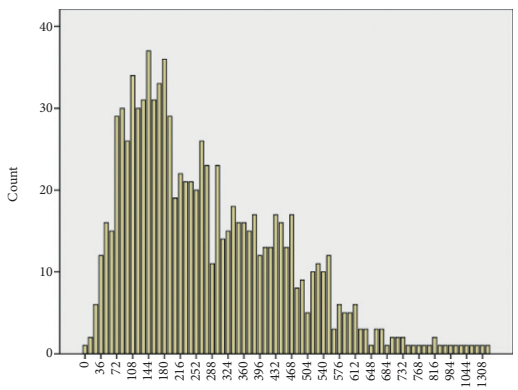

rate of changing out lanes (times)

(b)

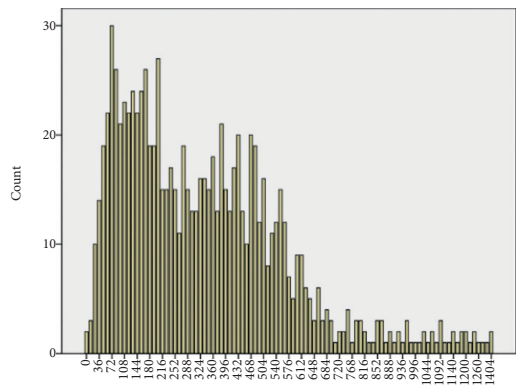

rate of changing out lanes (times)

(c)

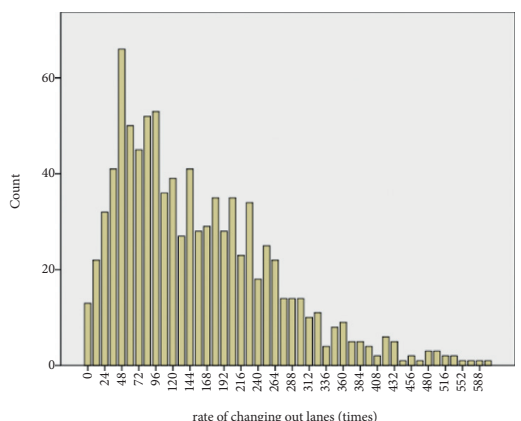

(d)
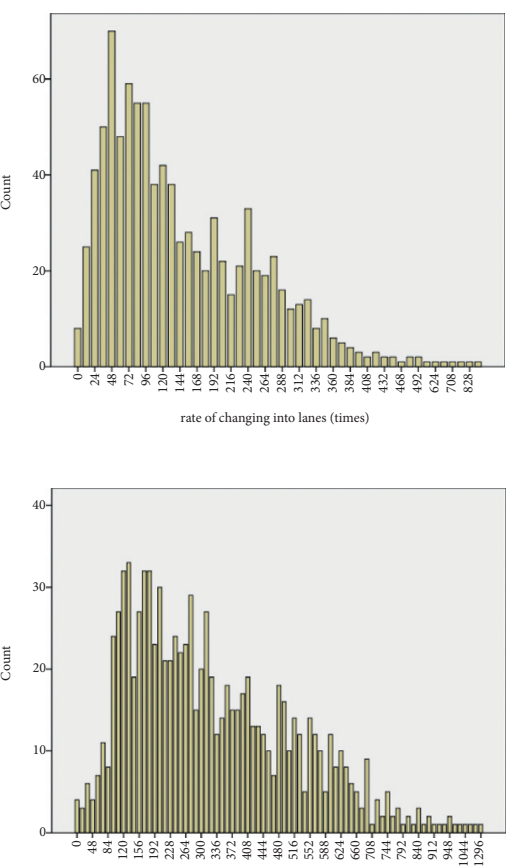

rate of changing into lanes (times)

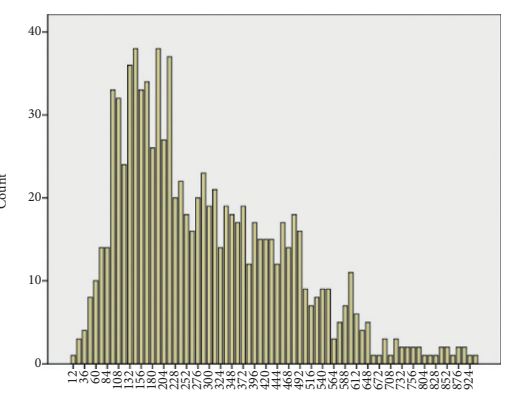

rate of changing into lanes (times)

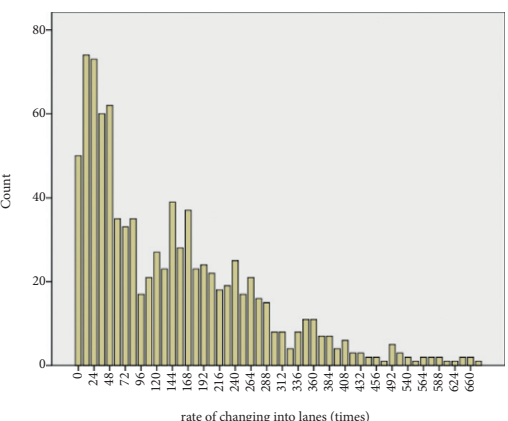

Figure 4: Data distribution histogram. (a) The histogram of Lane 1 speed, the rate of changing into lanes, and the rate of changing out of lanes. (b) The histogram of Lane 2 speed, the rate of changing into lanes, and the rate of changing out of lanes. (c) The histogram of Lane 3 speed, the rate of changing into lanes, and the rate of changing out of lanes. (d) The histogram of Lane 4 speed, the rate of changing into lanes, and the rate of changing out of lanes.

In the formula, $Z$ is the interpolation in time $t_{j}$, location $x_{i} ; t_{a}$ is the first valid data in $x_{i}$ location, $t_{1}$ is the initial moment; $t_{p}$ is end time; and $x_{i}$ is the place where interpolation needs to be performed.
In Figure 4, the data distribution is relatively discrete. We use histograms to describe the data characteristics. The speed is concentrated within $100 \mathrm{~km} / \mathrm{h}$. This is mainly due to the maximum speed limit (which is $100 \mathrm{~km} / \mathrm{h}$ ) on 
the third ring expressway in Chengdu. The data distribution of lane change-in rate and lane change-out rate is slightly different in each lane. From the shape of the plot, the speed in each lane is similar, but the rate of changing out of lanes and the rate of changing into lanes in each lane are different. The shapes in Lane 2 and Lane 3 are similar, while the shapes in Lane 1 and Lane 4 are different. For speed, the speed limit is used in all lanes. For lanechanging behavior, Lane 1 is the lane farthest from the entrance ramp and exit ramp, Lane 4 is the lane connecting the entrance ramp and exit ramp, and Lane 2 and Lane 3 are the connecting lanes of Lane 1 and Lane 4 . Therefore, the shapes of Lane 2 and Lane 3 are similar, while the shapes of Lane 1 and Lane 4 are different. In addition, Lane 1 is the lane less affected by the entrance ramp and exit ramp, and Lane 4 is the lane affected by the entrance ramp and exit ramp. These characteristics are shown in Figure 4 . The discrete of the lane-changing rate in Lane 4 is more than that in Lane 1. The speed, the rate of changing out of lanes, and the rate of changing into lanes in each lane show partial normal distributions. This distribution is very common on the road. The data distribution shows that the data collected from videos are really effective. The collected data can be used for the establishment of the simulation model.

2.2. Simulation Model. In order to study the relationship between the lane-changing behavior and speed under different penetration rates of autonomous vehicles on urban expressways, we used the third ring road in Chengdu, China, as a benchmark and established a simulation model of the urban expressway. The simulation model takes the ring-shaped urban expressway as the object. In order to make the simulation model close to the real road, we used 9 road sections according to the previously collected data. By simplifying the road network, only the exits and entrances are retained. Finally, a simulation model is established.

Using sumo as the platform, the road section is set as a one-way 4 lane. In previous studies, we found that the lanechanging behavior has an impact on the speed, but there are a slight effect in the free flow and more effect in large traffic flow. In order to increase enough flow, each section has 4 entrances and 1 exit. The road section setting is shown in Figure 5.

In Figure 5, different types of vehicles are used in the simulation model. In order to better simulate the real traffic, the vehicle types are set to four types of large trucks, medium trucks, cars, and autonomous vehicles. The autonomous vehicle types are uniform in the model. We used the CACC model to simulate the autonomous vehicle and the Krauss model to simulate the human-driving vehicle. In the road network, each section contains 4 entrances and one exit. The distance between the ramps is $1 \mathrm{~km}$, the simulation distance of each section is $5 \mathrm{~km}$, and the simulation distance of the whole road is $45 \mathrm{~km}$, which is close to the length of the third ring expressway of Chengdu (the length is $51 \mathrm{~km}$ ). The simulation time is $86,400 \mathrm{~s}$ (that is $24 \mathrm{~h}$ ). The simulation time period is 4 hours in the morning and 4 hours in the afternoon of the working day in large traffic flow. The simulation step is $0.1 \mathrm{~s}$. The tranCI is used to add different traffic flow to different intersections of the road. The collection time interval is 5 minutes, and the collected data in each lane include the speed, the rate of changing out lanes, and the rate of changing into lanes. The groups of collected data are 2,591 groups.

In order to verify the applicability of the simulation model, the first simulation involved three vehicle types: large trucks, medium trucks, and cars. The distribution of simulation data is shown in Figure 6.

In Figure 6, the data distribution is relatively discrete and similar to the empirical data. The rate of changing into lanes and the rate of changing out of lanes are relatively similar. In addition, the shapes of the simulation data and the empirical data (Figure 4) have a slight difference. The main reason is that the empirical data contain data in small traffic flow. In the simulation model, we only simulated the large traffic flow. There is a certain gap between the simulated data and the empirical data. But the data distributions are partial normal distributions.

In order to verify the similarity between the simulation model and the real traffic state, we drew diagrams of the relationship between the speed and the rate of changing out of lanes, and the relationship between the speed and the rate of changing into lanes of simulation data and empirical data, as shown in Figure 7.

In Figure 7, the data of the plots in the left part are collected from empirical research, and the data of the plots in the right part are collected by the simulation model. From the form of data, the shape and aggregation state of the empirical data are similar to that of the simulation data, except for group number, which is collected in simulations is more than that in empirical research. That is, from the view of data relationships, the data representation has a certain degree of similarity in empirical and simulation methods. Combining the histogram graphs and the plots of the relationships, we believe that the established simulation model can be used to study the relationship between lane-changing behavior and speed under different autonomous vehicle penetration rates.

\subsection{Experiment}

2.3.1. Experimental Design. Through the established simulation model, the experiment is designed to study the relationship between lane-changing behavior and speed in a circular traffic network under different autonomous vehicle penetration rates. Due to the addition of autonomous vehicles, the lane-changing behavior of vehicles is slightly different from that of human-driving vehicles. We would like to know whether different penetration rates of autonomous vehicles have an impact on the speed, the rate of changing out of lanes, and the rate of changing into lanes in the traffic. Through the data characteristics, we would like to know the relationship between speed and lane-changing behavior in mixed traffic. In the experiments, car-following behavior is mostly adopted, unless there is an obstacle in front of the lane-changing behavior must be performed. 


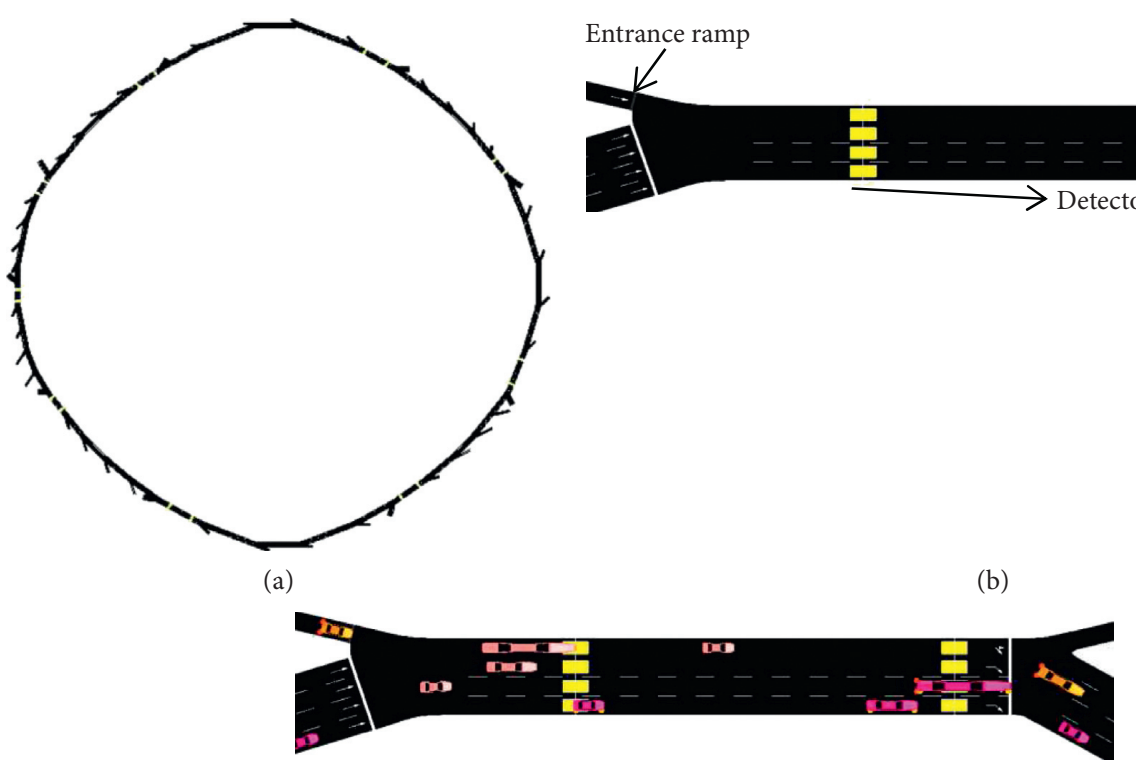

(c)

FIGURE 5: Schematic diagram of simulation modeling. (a) Road network model of 9 sections established by simulation. (b) Schematic diagram of the road section including the detector. (c) A road running diagram with one exit, one entrance, and two detectors.
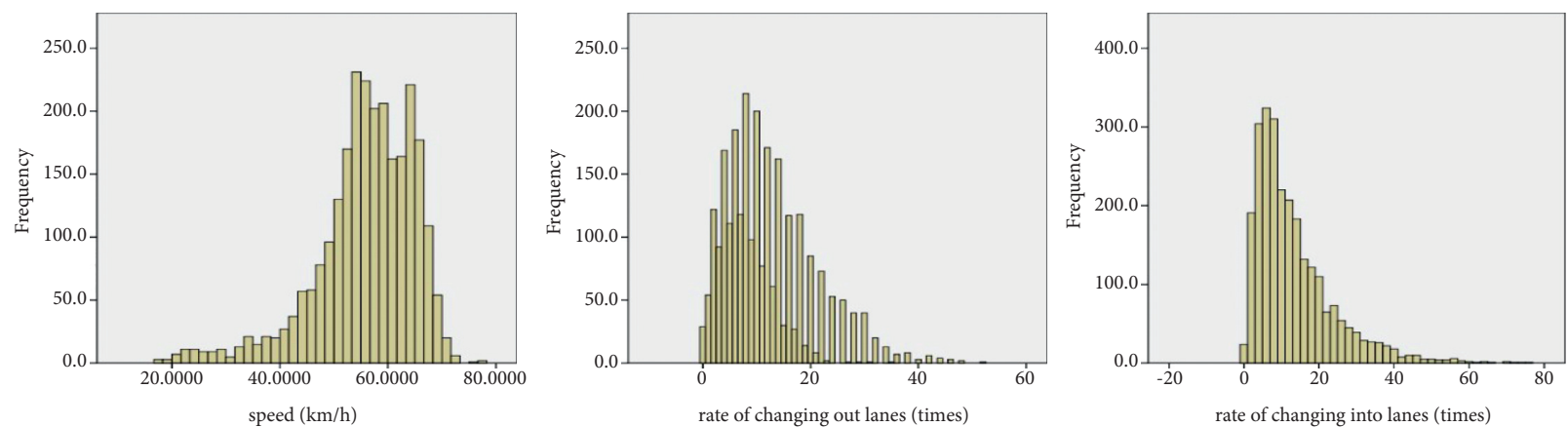

(a)
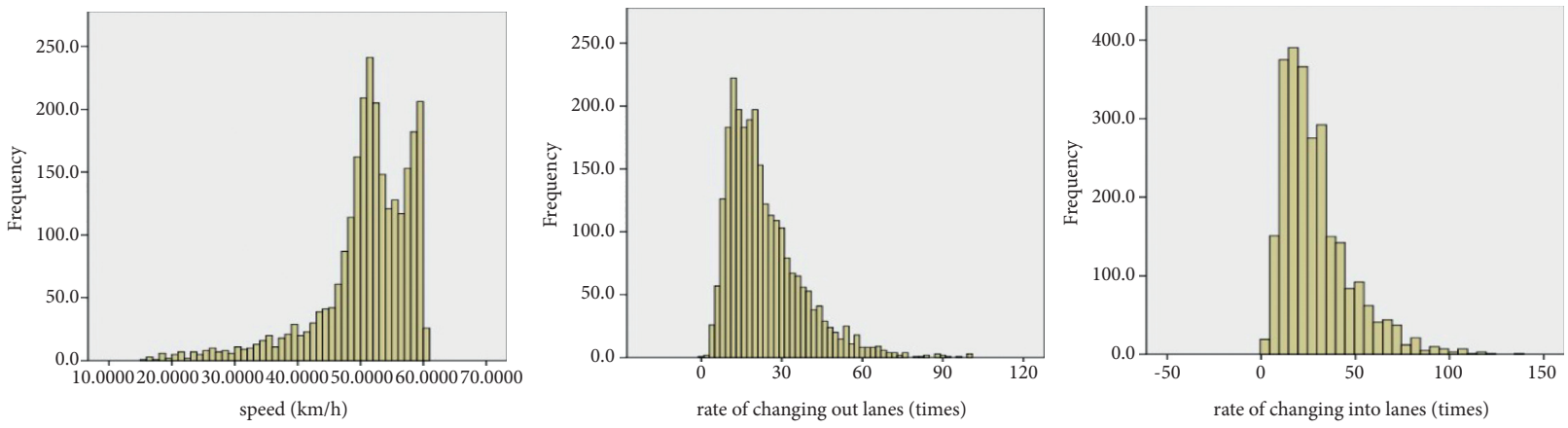

(b)

Figure 6: Continued. 

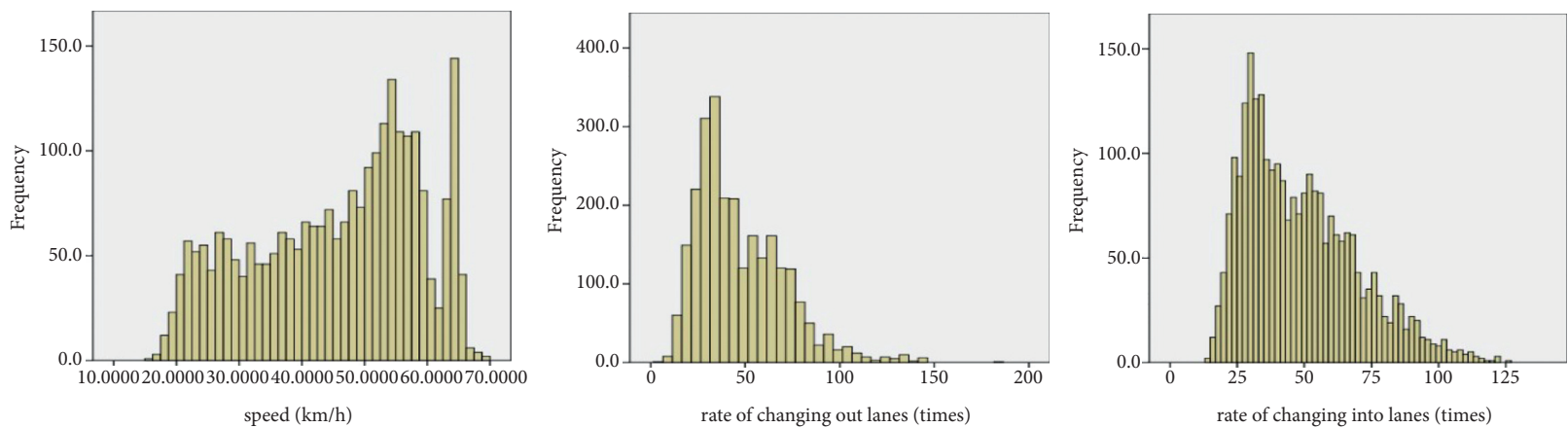

(c)
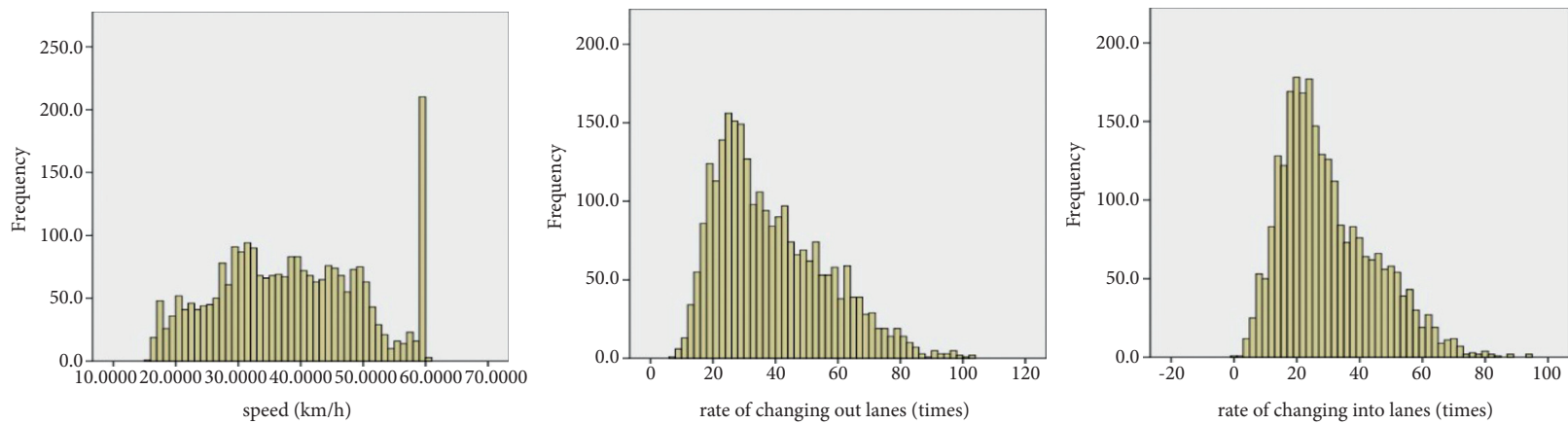

(d)

Figure 6: Simulation data distribution histogram. (a) The histogram of Lane 1 speed, the rate of changing into lanes, and the rate of changing out of lanes. (b) The histogram of Lane 2 speed, the rate of changing into lanes, and the rate of changing out of lanes. (c) The histogram of Lane 3 speed, the rate of changing into lanes, and the rate of changing out of lanes. (d) The histogram of Lane 4 speed, the rate of changing into lanes, and the rate of changing out of lanes.

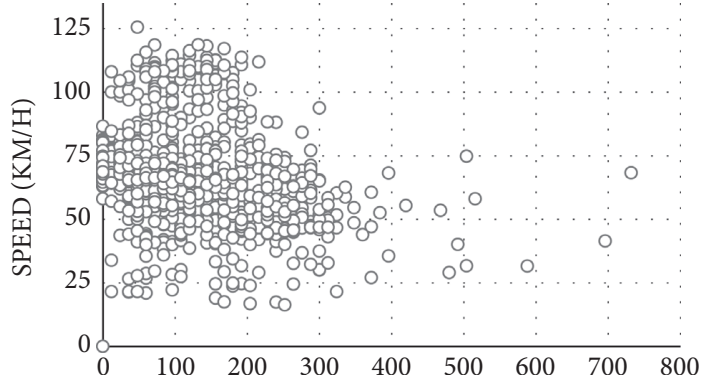

THE RATE OF CHANGING OUT LANES (TIMES)

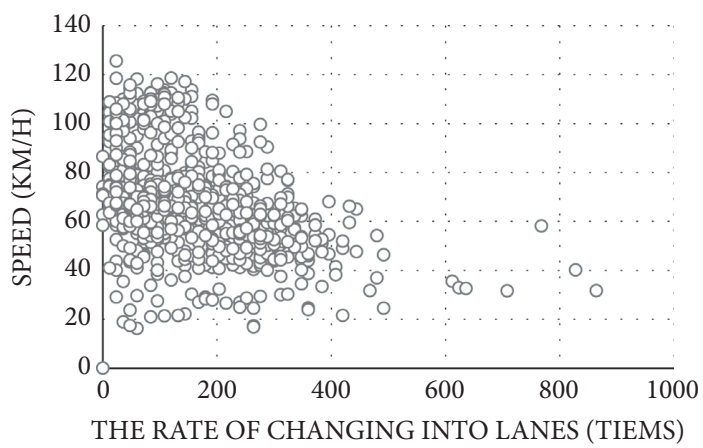

Empirical data in Lane 1
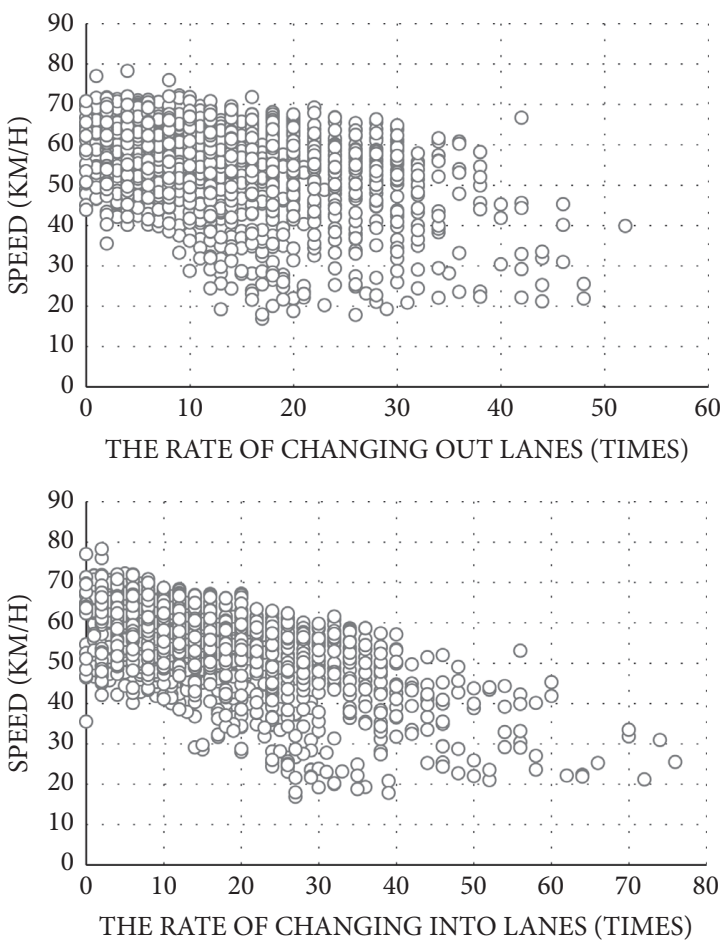

Simulation data in Lane 1

(a)

Figure 7: Continued. 

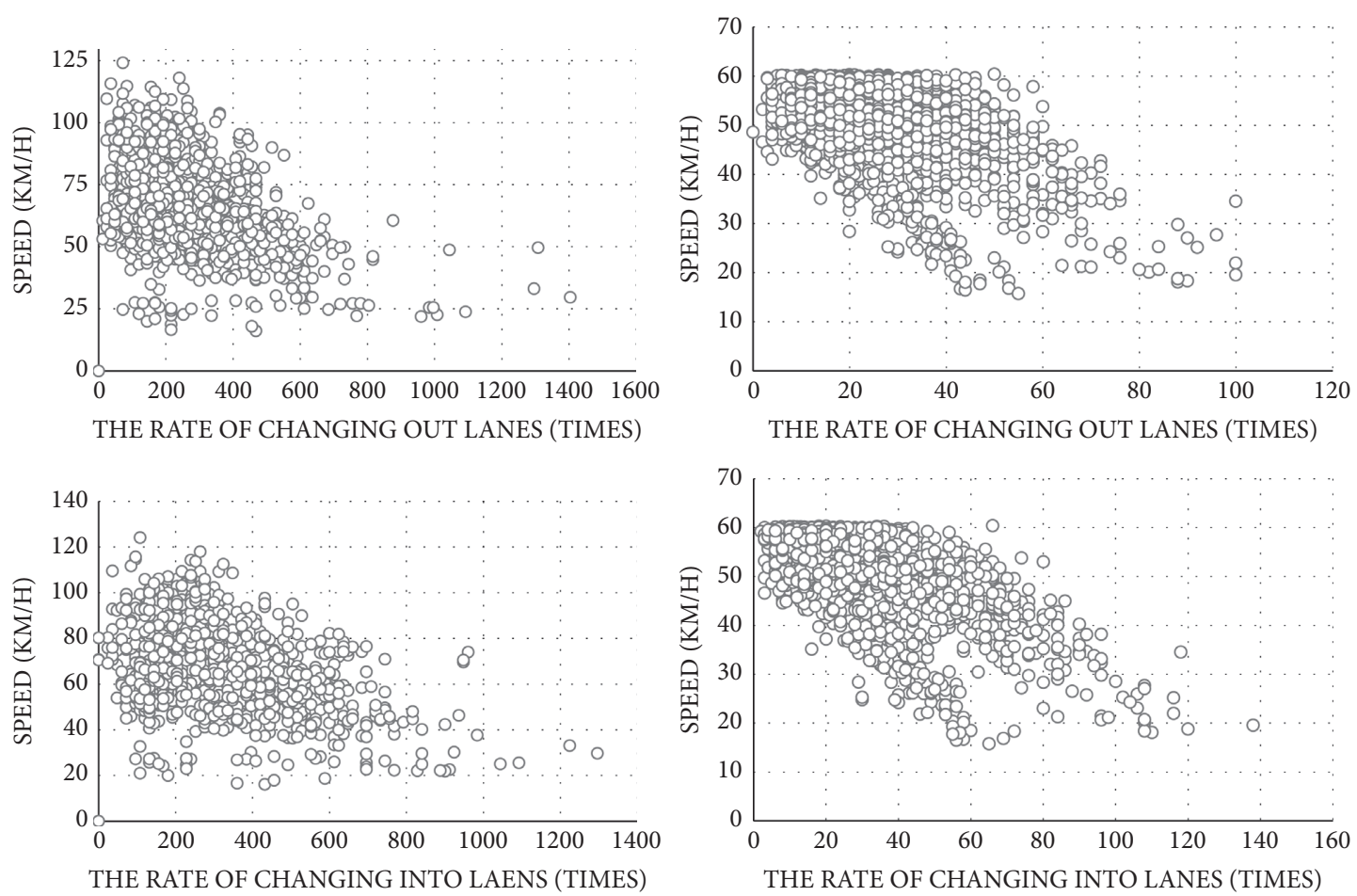

Empirical data in Lane 2

Simulation data in Lane 2

(b)
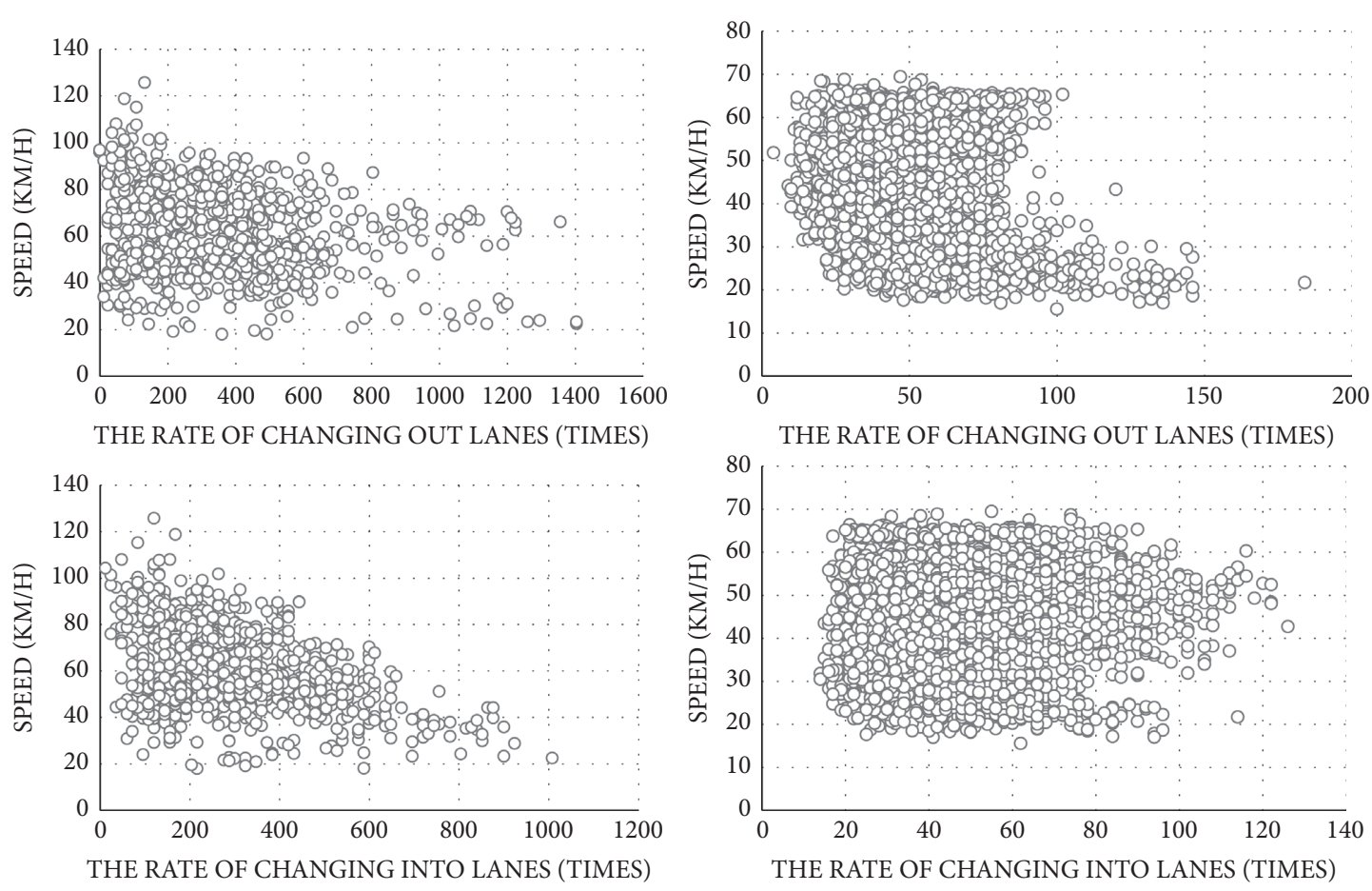

Empirical data in Lane 3

Simulation data in Lane 3

(c)

Figure 7: Continued. 

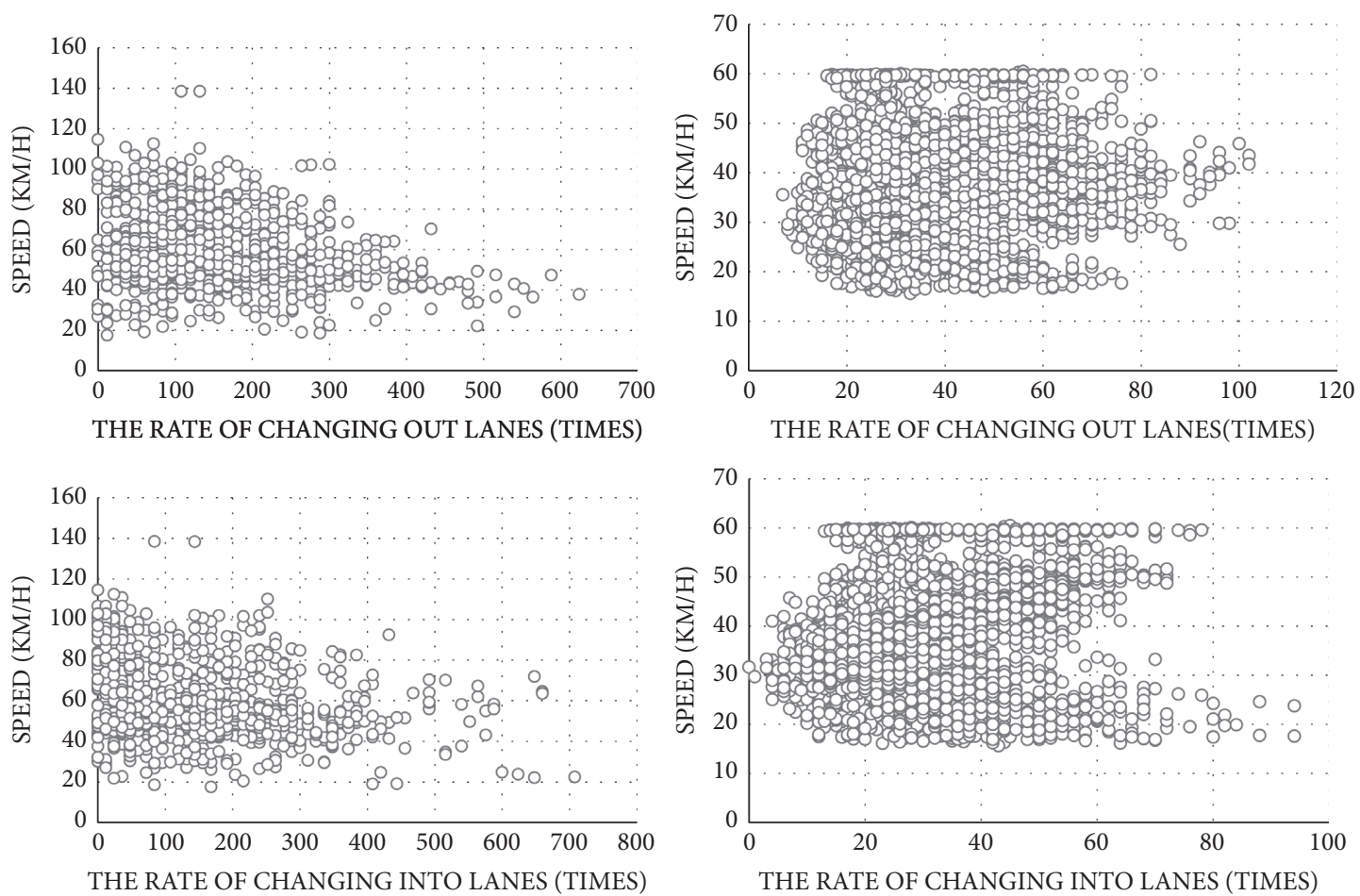

Empirical data in Lane 4

Simulation data in Lane 4

(d)

FIGURE 7: A scatter diagram of the relationship between the speed and the rate of changing out of lanes, and the relationship between the speed and rate of changing into lanes in each lane in the empirical data and simulation data. (a) The scatter plot of Lane 1. (b) The scatter plot of Lane 2. (c) The scatter plot of Lane 3. (d) The scatter plot of Lane 4.

Therefore, in the simulation process, CACC vehicles are used to simulate autonomous vehicles. The human-driving vehicles used the DK2008 model to change lanes. The simulation environment setting is consistent with the first simulation.

The experimental steps are as follows:

Step1. Different proportions of CACC vehicles $(10 \%, 20 \%$, $30 \%, 40 \%, 50 \%, 60 \%, 70 \%, 80 \%$, and $90 \%$, respectively) are added to the ring road for simulation experiments, using $86,400 \mathrm{~s}$ as the simulation time and step length of $0.1 \mathrm{~s}$. The collection time interval is $5 \mathrm{~min}$. The data of the speed, the rate of changing out of lanes, and the rate of changing into lanes are collected.

Step2. According to statistical data, the relationship between the speed and the rate of changing out of lanes, and between the speed and the rate of changing into lanes under different penetration rates of autonomous vehicles are analyzed.

Step3. The final conclusion is drawn based on the previous analysis.

2.3.2. Experimental Results. Through the design of the experiment, we collected the data of speed, the rate of changing into lanes, and the rate of changing out of lanes by the smooth operation of the experiment. In order to better analyze the relationship between speed and lane change behavior, the characteristics of the collected data are analyzed to verify the accuracy and effectiveness of the data. The data analysis can be shown in the statistical description data in Tables 2 4.

In Table 2, the data representations of Lane 1 and Lane 2 are relatively close. The average speed slightly decreases with the increase in the penetration rate of autonomous vehicles. When the penetration rates are $10 \%$ and $30 \%$, the average speed drops by $0.1 \%$, respectively. When the penetration rate increases to $40 \%$, the average speed is increased by $5 \%$, which is compared with the penetration rate of $30 \%$. Compared with no autonomous vehicle penetration, the average speed of Lane 1 is increased by $2 \%$, and of Lane 2 is increased by $4 \%$. When the penetration rate increases to $90 \%$, the average speed increases by $4 \%$ compared to the penetration rate of $40 \%$, by $6 \%$ in Lane1, and by $8 \%$ in Lane 2 compared to no autonomous vehicle penetration. However, when the penetration rates increase, the median speed slightly increases, and the speed mode does not change much. About $75 \%$ of speed has decreased, and $25 \%$ of speed has increased. Those representations show that with the continuous penetration of autonomous vehicles, the speed tends to converge toward the speed mode, and the median speed gradually moves closer to the speed mode. But it is still different from the average speed, and it is still non-normally distributed. Lane 1 
TABLE 2: The statistical description table of the speed of each lane under different autonomous vehicle penetration rates.

\begin{tabular}{|c|c|c|c|c|c|c|c|c|c|c|c|}
\hline & & $p=0 \%$ & $p=10 \%$ & $p=20 \%$ & $p=30 \%$ & $p=40 \%$ & $p=50 \%$ & $p=60 \%$ & $p=70 \%$ & $p=80 \%$ & $p=90 \%$ \\
\hline \multirow{7}{*}{ Lane1 } & Mean value & 55.85 & 55.45 & 55.08 & 54.046 & 54.47 & 54.630 & 57.20 & 58.745 & 59.72 & 60.54 \\
\hline & Standard error & 0.182 & 0.190 & 0.191 & 0.203 & 0.193 & 0.185 & 0.130 & 0.104 & 0.083 & 0.075 \\
\hline & Median & 56.98 & 57.18 & 57.37 & 56.735 & 57.29 & 57.235 & 58.6 & 59.46 & 60.04 & 60.44 \\
\hline & Mode & 64.95 & 58.64 & 64.83 & 64.405 & 61.33 & 61.73 & 60.43 & 61.615 & 61.96 & 60.99 \\
\hline & Variance & 85.90 & 9.706 & 95.13 & 106.96 & 96.56 & 89.340 & 44.19 & 28.32 & 17.99 & 14.92 \\
\hline & $75 \%$ & 70.26 & 94.20 & 68.89 & 68.645 & 68.09 & 67.605 & 67.91 & 68.5 & 68.59 & 69.56 \\
\hline & $25 \%$ & 23.49 & 69.68 & 24.26 & 23.135 & 23.90 & 25.825 & 34.99 & 40.35 & 45.65 & 47.58 \\
\hline \multirow{7}{*}{ Lane2 } & Mean value & 50.85 & 23.69 & 50.52 & 49.80 & 50.30 & 50.44 & 52.98 & 54.27 & 55.14 & 55.90 \\
\hline & Standard error & 0.151 & 50.63 & 0.164 & 0.176 & 0.166 & 0.159 & 0.104 & 0.079 & 0.059 & 0.048 \\
\hline & Median & 51.94 & 0.164 & 52.64 & 52.36 & 52.595 & 52.6 & 54.03 & 54.93 & 55.62 & 56.25 \\
\hline & Mode & 52.47 & 52.4 & 54.44 & 52.05 & 49.985 & 56.495 & 54.79 & 55.71 & 56.89 & 56.74 \\
\hline & Variance & 59.08 & 51.92 & 70.37 & 80.65 & 71.64 & 65.79 & 28.37 & 16.43 & 9.139 & 6.029 \\
\hline & $75 \%$ & 60.00 & 8.194 & 59.86 & 59.805 & 59.705 & 59.73 & 59.75 & 59.845 & 59.77 & 59.93 \\
\hline & $25 \%$ & 21.96 & 67.19 & 21.90 & 21.585 & 22.985 & 24.58 & 33.29 & 38.84 & 45.60 & 48.53 \\
\hline \multirow{7}{*}{ Lane3 } & Mean value & 45.59 & 59.94 & 39.96 & 36.84 & 35.66 & 35.22 & 35.69 & 38.31 & 40.25 & 42.80 \\
\hline & Standard error & 0.258 & 21.54 & 0.239 & 0.221 & 0.203 & 0.204 & 0.181 & 0.1726 & 0.154 & 0.123 \\
\hline & Median & 48.1 & 42.91 & 39.68 & 36.08 & 35.1 & 34.065 & 35.54 & 39.055 & 41.07 & 43.29 \\
\hline & Mode & 54.55 & 0.256 & 30.47 & 29.855 & 36.135 & 38.845 & 36.315 & 42.57 & 42.80 & 45.11 \\
\hline & Variance & 173.4 & 44.09 & 148.7 & 127.13 & 107.05 & 108.04 & 85.46 & 76.67 & 61.55 & 39.78 \\
\hline & $75 \%$ & 65.43 & 24.91 & 64.62 & 63.25 & 59.82 & 59.765 & 58.005 & 57.65 & 57.37 & 56.30 \\
\hline & $25 \%$ & 19.26 & 13.03 & 19.10 & 18.39 & 18.5 & 18.52 & 18.825 & 20.145 & 21.65 & 25.77 \\
\hline \multirow{7}{*}{ Lane4 } & Mean value & 38.46 & 169.8 & 33.81 & 31.24 & 30.14 & 29.618 & 29.05 & 31.01 & 32.97 & 36.65 \\
\hline & Standard error & 0.228 & 65.65 & 0.211 & 0.198 & 0.186 & 0.189 & 0.184 & 0.191 & 0.186 & 0.164 \\
\hline & Median & 38.05 & 18.67 & 32.98 & 30.235 & 29.29 & 28.14 & 28.125 & 30.975 & 33.88 & 38.82 \\
\hline & Mode & 59.60 & 36.30 & 44.85 & 22.36 & 20.56 & 31.455 & 35.215 & 18.945 & 40.19 & 42.60 \\
\hline & Variance & 135.0 & 0.226 & 116.2 & 101.62 & 90.056 & 92.974 & 88.243 & 94.86 & 89.75 & 70.30 \\
\hline & $75 \%$ & 59.79 & 35.85 & 59.5 & 57.385 & 53.73 & 54.195 & 51.11 & 50.155 & 50.76 & 51.16 \\
\hline & $25 \%$ & 17.16 & 31.83 & 16.35 & 15.215 & 15.2 & 14.545 & 13.41 & 12.995 & 13.22 & 16.26 \\
\hline
\end{tabular}

TABle 3: The statistical description table of the rate of changing out of lanes of each lane under different autonomous vehicle penetration rates.

\begin{tabular}{|c|c|c|c|c|c|c|c|c|c|c|c|}
\hline & & $p=0 \%$ & $p=10 \%$ & $p=20 \%$ & $p=30 \%$ & $p=40 \%$ & $p=50 \%$ & $p=60 \%$ & $p=70 \%$ & $p=80 \%$ & $p=90 \%$ \\
\hline \multirow{7}{*}{ Lane1 } & Mean value & 11.76 & 8.07 & 8.151 & 8.31 & 8.176 & 8.08 & 6.852 & 5.92 & 5.5 & 4.81 \\
\hline & Standard error & 0.158 & 0.087 & 0.083 & 0.082 & 0.076 & 0.076 & 0.066 & 0.059 & 0.056 & 0.052 \\
\hline & Median & 10 & 8 & 8 & 8 & 8 & 8 & 6 & 6 & 5 & 4 \\
\hline & Mode & 8 & 6 & 6 & 6 & 6 & 6 & 5 & 5 & 4 & 4 \\
\hline & Variance & 65.10 & 4.445 & 17.88 & 17.52 & 15.04 & 15.03 & 11.60 & 9.02 & 8.242 & 7.08 \\
\hline & $75 \%$ & 38 & 21 & 20 & 22 & 20 & 20 & 16 & 15 & 14 & 13 \\
\hline & $25 \%$ & 0 & 1 & 1 & 2 & 1 & 2 & 1 & 1 & 1 & 0 \\
\hline \multirow{7}{*}{ Lane2 } & Mean value & 23.35 & 16.11 & 16.73 & 17.64 & 17.65 & 17.98 & 17.25 & 16.06 & 15.28 & 14.55 \\
\hline & Standard error & 0.280 & 0.160 & 0.162 & 0.181 & 0.166 & 0.174 & 0.166 & 0.157 & 0.143 & 0.132 \\
\hline & Median & 20 & 14 & 15 & 16 & 16 & 16 & 15 & 15 & 14 & 13 \\
\hline & Mode & 18 & 14 & 13 & 12 & 14 & 13 & 12 & 11 & 11 & 12 \\
\hline & Variance & 203.5 & 8.169 & 68.341 & 84.92 & 71.40 & 78.79 & 71.99 & 63.98 & 53.22 & 45.29 \\
\hline & $75 \%$ & 70 & 44 & 44 & 49 & 46 & 47 & 44 & 43 & 39 & 36 \\
\hline & $25 \%$ & 4 & 4 & 4 & 5 & 5 & 4 & 4 & 4 & 3 & 3 \\
\hline \multirow{7}{*}{ Lane3 } & Mean value & 47.30 & 34.71 & 37.64 & 41.20 & 42.63 & 44.01 & 47.12 & 46.88 & 45.84 & 44.11 \\
\hline & Standard error & 0.458 & 0.241 & 0.260 & 0.298 & 0.291 & 0.309 & 0.334 & 0.339 & 0.3165 & 0.280 \\
\hline & Median & 42 & 32 & 35 & 38 & 40 & 41 & 44 & 43 & 43 & 42 \\
\hline & Mode & 36 & 30 & 33 & 32 & 32 & 37 & 42 & 36 & 41 & 40 \\
\hline & Variance & 543.7 & 12.27 & 175.27 & 230.9 & 218.80 & 247.8 & 290.7 & 297.9 & 259.27 & 203.44 \\
\hline & $75 \%$ & 126 & 77 & 83 & 89 & 91 & 93 & 98 & 99 & 94 & 87 \\
\hline & $25 \%$ & 14 & 16 & 17 & 18 & 19 & 19 & 20 & 20 & 20 & 19 \\
\hline \multirow{7}{*}{ Lane4 } & Mean value & 38.01 & 25.35 & 25.28 & 26.01 & 26.57 & 26.88 & 27.16 & 25.51 & 23.64 & 20.22 \\
\hline & Standard error & 0.342 & 0.148 & 0.148 & 0.152 & 0.163 & 0.164 & 0.173 & 0.180 & 0.173 & 0.156 \\
\hline & Median & 34 & 24 & 24 & 25 & 26 & 26 & 26 & 25 & 23 & 19 \\
\hline & Mode & 24 & 22 & 22 & 22 & 22 & 24 & 25 & 20 & 19 & 18 \\
\hline & Variance & 304.2 & 7.575 & 56.978 & 59.91 & 69.539 & 70.16 & 78.22 & 83.96 & 77.67 & 63.738 \\
\hline & $75 \%$ & 86 & 46 & 45 & 46 & 49 & 49 & 51 & 51 & 46 & 41 \\
\hline & $25 \%$ & 12 & 11 & 11 & 11 & 11 & 11 & 11 & 9 & 8 & 6 \\
\hline
\end{tabular}


TABLE 4: The statistical description table of the rate of changing into lanes of each lane under different autonomous vehicle penetration rates.

\begin{tabular}{|c|c|c|c|c|c|c|c|c|c|c|c|}
\hline & & $p=0 \%$ & $p=10 \%$ & $p=20 \%$ & $p=30 \%$ & $p=40 \%$ & $p=50 \%$ & $p=60 \%$ & $p=70 \%$ & $p=80 \%$ & $p=90 \%$ \\
\hline \multirow{7}{*}{ Lane1 } & Mean value & 13.05 & 9.231 & 9.814 & 10.50 & 10.543 & 10.651 & 9.592 & 8.370 & 7.538 & 6.872 \\
\hline & Standard error & 0.212 & 0.127 & 0.125 & 0.130 & 0.123 & 0.121 & 0.104 & 0.091 & 0.076 & 0.065 \\
\hline & Median & 10 & 7 & 8 & 9 & 9 & 9 & 9 & 8 & 7 & 6 \\
\hline & Mode & 8 & 5 & 7 & 6 & 7 & 6 & 8 & 6 & 5 & 6 \\
\hline & Variance & 116.7 & 6.480 & 41.001 & 44.08 & 39.59 & 38.07 & 28.26 & 21.67 & 15.17 & 11.08 \\
\hline & $75 \%$ & 52 & 31 & 31 & 32 & 31 & 30 & 26 & 24 & 20 & 16 \\
\hline & $25 \%$ & 1 & 1 & 1 & 1 & 1 & 1 & 1 & 1 & 1 & 1 \\
\hline \multirow{7}{*}{ Lane2 } & Mean value & 29.15 & 20.61 & 21.63 & 23.15 & 23.64 & 24.01 & 23.55 & 22.05 & 20.72 & 19.00 \\
\hline & Standard error & 0.363 & 0.207 & 0.202 & 0.221 & 0.210 & 0.215 & 0.214 & 0.205 & 0.186 & 0.162 \\
\hline & Median & 24 & 18 & 20 & 21 & 21 & 22 & 21 & 20 & 19 & 18 \\
\hline & Mode & 28 & 15 & 15 & 16 & 17 & 16 & 20 & 15 & 18 & 15 \\
\hline & Variance & 342.3 & 10.53 & 106.62 & 126.7 & 114.95 & 120.43 & 118.8 & 109.86 & 89.82 & 67.95 \\
\hline & $75 \%$ & 94 & 55 & 54 & 60 & 56 & 57 & 56 & 55 & 49 & 43 \\
\hline & $25 \%$ & 5 & 5 & 6 & 6 & 6 & 7 & 6 & 5 & 5 & 4 \\
\hline \multirow{7}{*}{ Lane3 } & Mean value & 48.31 & 32.23 & 32.21 & 33.18 & 33.68 & 34.22 & 34.82 & 33.20 & 31.38 & 27.90 \\
\hline & Standard error & 0.414 & 0.171 & 0.173 & 0.186 & 0.194 & 0.201 & 0.216 & 0.228 & 0.218 & 0.198 \\
\hline & Median & 44 & 31 & 31 & 32 & 32 & 33 & 34 & 32 & 30 & 27 \\
\hline & Mode & 52 & 29 & 28 & 25 & 28 & 32 & 34 & 32 & 27 & 23 \\
\hline & Variance & 445.6 & 8.72 & 77.707 & 90.13 & 97.904 & 104.14 & 121.5 & 135.56 & 123.7 & 101.79 \\
\hline & $75 \%$ & 108 & 55 & 55 & 59 & 62 & 62 & 65 & 66 & 62 & 55 \\
\hline & $25 \%$ & 17 & 16 & 16 & 16 & 16 & 15 & 15 & 12 & 12 & 9 \\
\hline \multirow{7}{*}{ Lane4 } & Mean value & 29.90 & 22.185 & 24.15 & 26.33 & 27.17 & 28.080 & 30.42 & 30.762 & 30.62 & 29.928 \\
\hline & Standard error & 0.298 & 0.142 & 0.152 & 0.167 & 0.163 & 0.177 & 0.195 & 0.202 & 0.199 & 0.194 \\
\hline & Median & 26 & 21 & 23 & 25 & 26 & 26 & 29 & 29 & 29 & 28 \\
\hline & Mode & 24 & 20 & 21 & 23 & 24 & 25 & 25 & 23 & 25 & 24 \\
\hline & Variance & 231.6 & 7.25 & 60.01 & 72.33 & 69.06 & 81.36 & 99.01 & 105.68 & 102.8 & 97.76 \\
\hline & $75 \%$ & 72 & 46 & 51 & 53 & 53 & 56 & 61 & 62 & 61 & 61 \\
\hline & $25 \%$ & 6 & 9 & 11 & 12 & 13 & 13 & 14 & 13 & 13 & 14 \\
\hline
\end{tabular}

and Lane 2 belong to the faster lanes. When autonomous vehicles enter the road, there will have a certain impact on the road speed. This is a slight downward trend. With the increase in penetration of autonomous vehicles, the average speed of the lanes will have a significant increase when the penetration rate is over $40 \%$, compared with no autonomous vehicles on the road. Lane 3 and Lane 4 are close to the ramps and have the influence of entrances and exits, so there will have a certain impact on the speed after the autonomous vehicle running on the road. In Table 2 , the average speed of Lane 3 drops by $12 \%$ under the $10 \%$ penetration rate of autonomous vehicles. When the penetration rates of autonomous vehicles continue to increase, the average speed still shows a downward trend. When the penetration rate reaches $40 \%$, the average speed has rebounded. When the penetration rate reaches $90 \%$, the average speed has risen by $12.7 \%$ compared to $40 \%$ of the autonomous vehicle penetration rate, but it is still $11 \%$ lower than the penetration rate of $0 \%$. The median speed slightly increased, the speed mode did not change much, the $75 \%$ speed did not change much, and the $25 \%$ speed increased. It shows that with the penetration of autonomous vehicles in Lane3, the speed is concentrated in the speed mode, and the median speed and the speed mode have a similar trend with the increase in penetration rates, but there is still a gap with the average speed. So the speed is still non-normally distributed in Lane 3. However, compared with $0 \%$ of the penetration rate of autonomous vehicles, the average speed of Lane 3 has decreased. This is mainly because Lane 3 is responsible for a large number of lane change behaviors of vehicles from Lane 1 and Lane 2 that need to exit the road. So the lane changing behavior effect the average speed of Lane 3. Lane 4 is the lane directly connected to the entrances and exits. The average speed is most affected by the behavior of changing lanes. With the increased penetration rates of autonomous vehicles, the average speed decreases by $12 \%$ when the penetration rate of autonomous vehicles is $10 \%$. Then, the speed of decline increases with the increase in autonomous vehicle penetration rates. However, the average speed of Lane 4 will not increase until the penetration rate of autonomous vehicles is increased to $40 \%$. Although the average speed has increased when the penetration rate is increased to $90 \%$, it is still $14 \%$ lower than the penetration rate of $0 \%$. The median speed and speed mode slightly changed with the average speed but did not change much. The median speed and speed mode did not show a close trend due to the increase in the penetration rates of autonomous vehicles. The $75 \%$ speed and $25 \%$ speed slightly decrease with the increase in penetration rates, but the speed still converges toward the speed mode. Taking a comprehensive of the speeds in Table 2 from Lane 1 to Lane 4, with the increase in penetration rates of autonomous vehicles, the average speed shows a trend of decline at the first and then rise up. The changes in the median speed and speed mode are more obvious in Lane 1 and Lane 2 and are not obvious in Lane 3 and Lane 4 . But the median speed and speed mode have a trend of approaching 
as the penetration rates of autonomous vehicles increase, except for data in Lane 4 . The $75 \%$ speed has decreased, and the $25 \%$ speed has increased except for the decrease in Lane 4. However, it shows that the speed is converging toward the speed mode as the penetration rates of autonomous vehicles increase.

The impact of autonomous vehicles on speed can be seen in Table 2. Different lanes play different roles in traffic. The lane-changing behavior is most affected in Lane 3 and Lane 4 , especially Lane 4 , which directly affects speed. It can be clearly seen in Figure 8 that the addition of autonomous vehicles has a greater impact on lane-changing behavior. It can also be proved from the statistical data in Tables 3 and 4 .

In Table 3, as the penetration rates of autonomous vehicles continue to increase, the average rate of changing out of lanes does not significantly change and has declined compared with $0 \%$ penetration rate. Except for Lane 4 , the median and mode of the rate of changing out of lanes tend to approach with the increase in penetration rates of autonomous vehicles, but there are still differences from the average rate of changing out of lanes, and the distribution is still non-normal. The rate of changing out of lanes in the $75 \%$ has decreased with the increase in penetration rates of autonomous vehicles, except for the significant decrease under the penetration rate of $10 \%$. But in the $25 \%$, the increases with the increase in penetration rates are not significant changes. It can be seen from the data changes of the rate of changing out of lanes that the increases in autonomous vehicles have a significant impact on multilane traffic, but as the penetration rates increase, the impact is not significant. In Table 4, this situation still occurs at the rate of changing into lanes. When the penetration rate of autonomous vehicles is $10 \%$, the changes in the average rate of changing into lanes are not obvious in Lane 4 and are obvious in the other three lanes. The decline is above $10 \%$ in the other three lanes. However, as the penetration rates of autonomous vehicles increase, the trend of changes is not obvious. Except for Lane 4, the median and mode of the rate of changing into lanes tend to approach with the increase in penetration rates of autonomous vehicles, but there are differences from the average rate of changing into lanes. The change in the median and mode of the rate of changing into lanes in Lane 4 is not obvious. The $75 \%$ of the rate of changing into lanes has no significant change with the increase in the penetration rates of autonomous vehicles, except for a significant drop in the penetration rate of $10 \%$. However, the changes in the $25 \%$ of the rate of changing into lanes in all lanes are not obvious. On the whole, the rate of changing into lanes and the rate of changing out of lanes tend to increase in Lane 1 Lane 3, while the data in Lane 4 slightly decrease. Lane 3, as the busiest lane on the road, is mainly responsible for vehicles, which enter or exit the road. With the increase in the penetration rates of autonomous vehicles, the rate of changing into lanes and the rate of changing out of lanes have declined, but most lane change behaviors still happened in Lane 3. At the same time, the lane change-in rate and lane change-out rate of Lane 2, Lane 3, and Lane 4 have a similar trend. The influence of lanechanging behavior in Lane 1 is relatively small because of the lane far away from the entrance and exit. With the increase in the penetration rates of autonomous vehicles, the rate of changing into lanes and the rate of changing out of lanes in Lane 1 decreased, but the decline is not very obvious.

Considering data in Tables 2-4, we found that on a circular closed 4-lane road with a large traffic flow in mixed traffic, the speed presents an obvious trend of first decline and then rise up. In different lanes, the different penetration rates of autonomous vehicles will have different effects on speed. The speed of the lane far away from the entrance and exit has increased when the penetration rate of autonomous vehicles reaches $40 \%$, compared with the penetration rate of $0 \%$. The speed of the lane closer to the entrance and exit is not significantly increased or even slightly decreased. At the same time, the rate of changing out of lanes and the rate of changing into lanes significantly decreased as the penetration rate of autonomous vehicles reached $10 \%$ and then did not significantly decrease as the penetration rates increased. Lane 3 is still the busiest lane among the four lanes, and the lane-changing behavior of Lane 4 does not significantly respond to the addition of autonomous vehicles. This phenomenon is consistent with the speed changes. At the same time, it shows that after the penetration rate of autonomous vehicles reaches $10 \%$, the penetration rate has little effect on the lane-changing behavior of each lane. With the increase in the penetration rates of autonomous vehicles, the speed of the lane far away from the entrance and exit has decreased before reaching 30\% penetration rate and has increased after the penetration rate exceeds $40 \%$, compared with $0 \%$ penetration rate. For the lane close to the entrance and exit, lane-changing behavior is still the main factor that affects the speed in each lane. A greater impact on the rate of changing into lanes and the rate of changing out of lanes only occurs when the penetration rate is $10 \%$. This situation shows that autonomous vehicles running on the road take a limited impact on lane-changing behavior. With the increase in the penetration rates of autonomous vehicles, the average speed of the lanes has decreased compared with $0 \%$ penetration rate. It shows that for the lane close to the entrance and exit, the autonomous vehicles actually affect the average speed of the lane. However, all data show that as the penetration rates of autonomous vehicles increase, there is a certain degree of convergence in the speed, the rate of changing into lanes, and the rate of changing out of lanes in each lane.

Through the above analysis, we believe that the collected data of the speed, the rate of changing out of lanes, and the rate of changing into lanes have certain changes and stability. The simulation model is valid. So the data can be used to study the relationship between speed and lane change rate. But the relationship requires further research and analysis.

\section{Results and Conclusions}

3.1. Analysis of the Relationship between Speed and Lane Change Rate in Mixed Traffic. After the previous analysis, we found that we can study the relationship between speed and the rate of changing out of lanes, and the relationship between speed and the rate of changing into lanes to research 

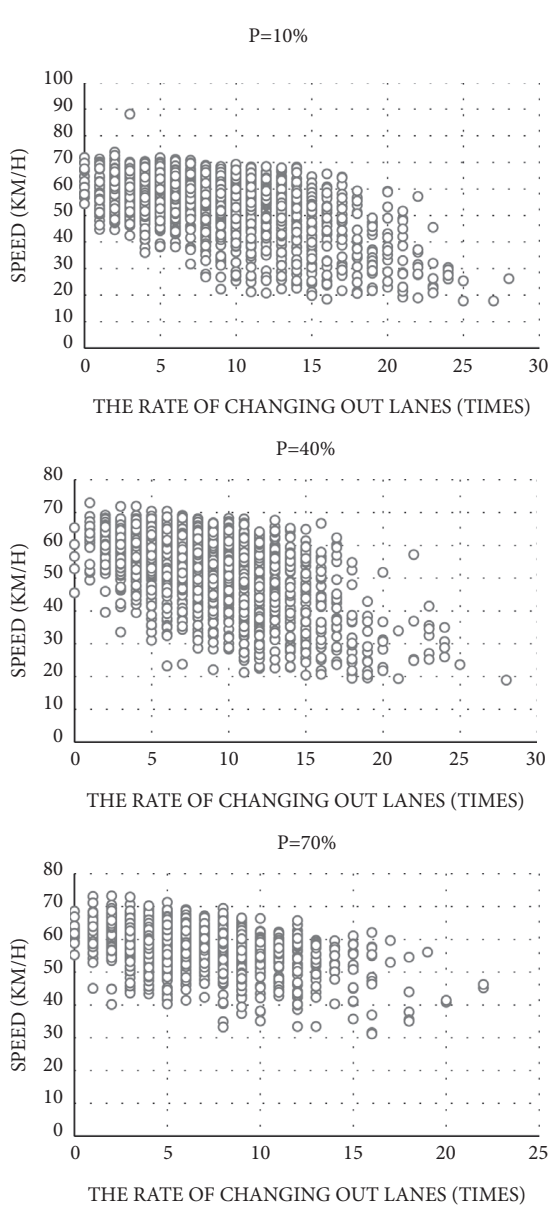
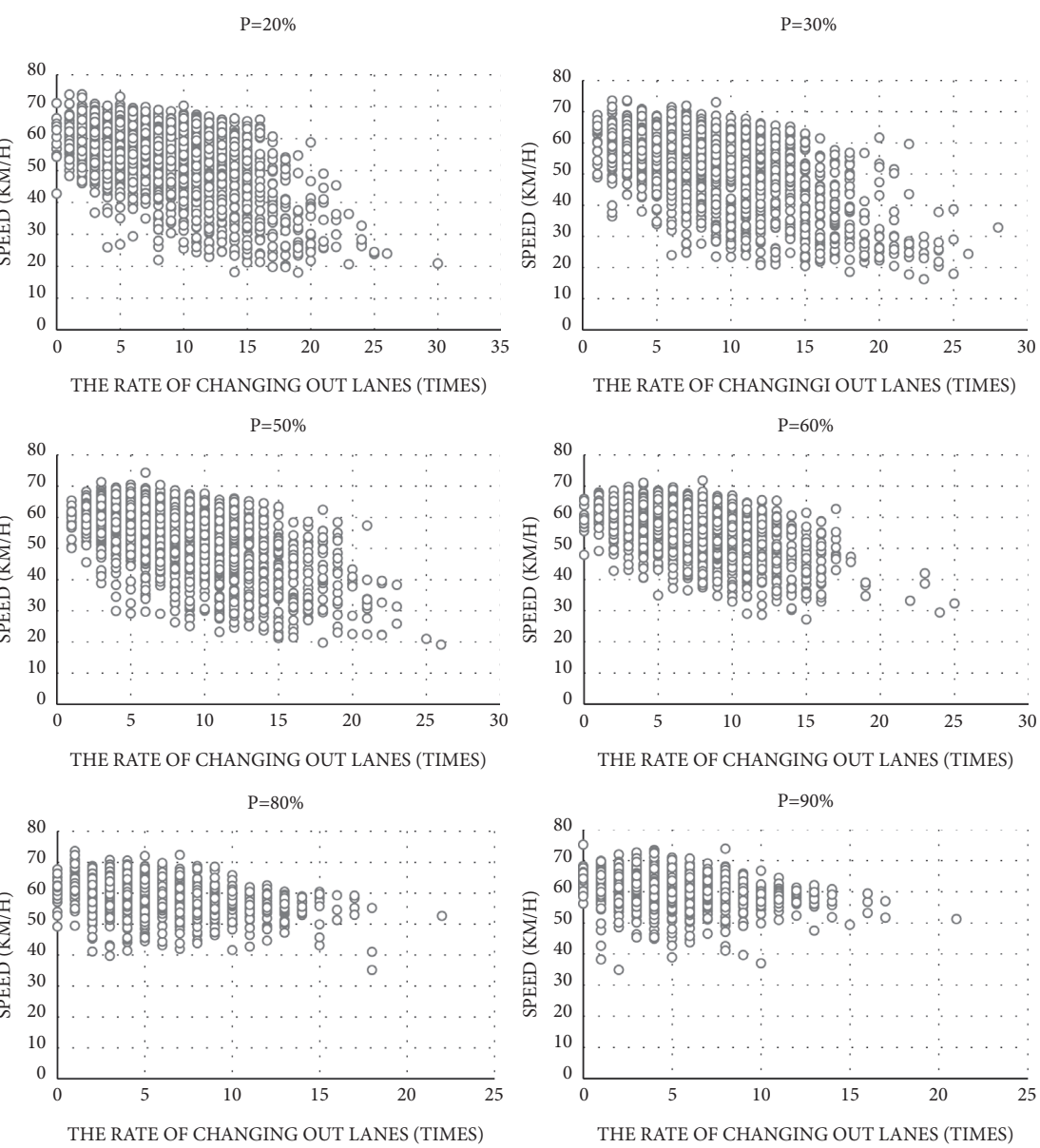

(a)

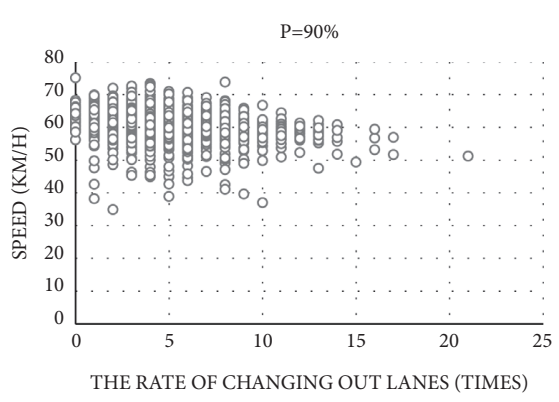

Figure 8: Continued. 


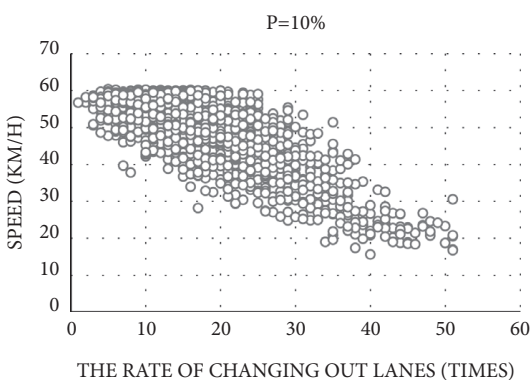

$\mathrm{P}=40 \%$

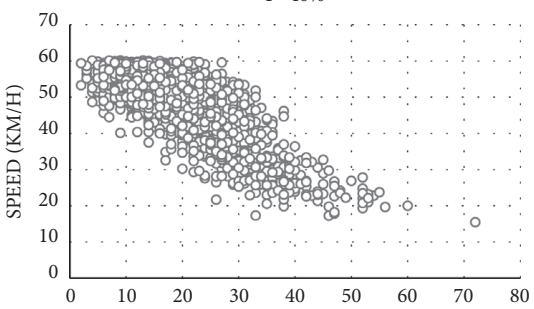

THE RATE OF CHANGING OUT LANES (TIMES) $\mathrm{P}=70 \%$

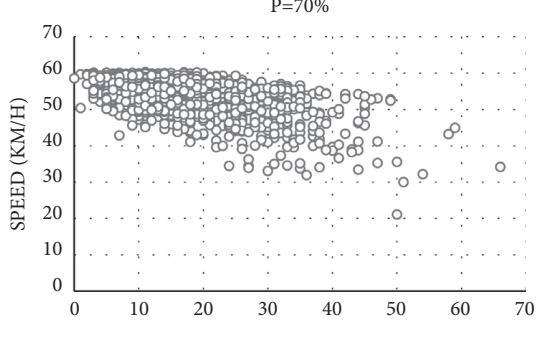

THE RATE OF CHANGING OUT LANES (TIMES)

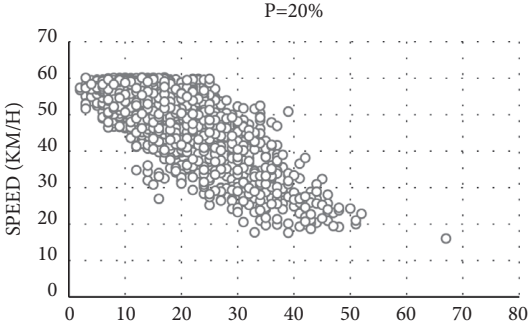

THE RATE OF CHANGING OUT LANES (TIMES)

$\mathrm{P}=50 \%$

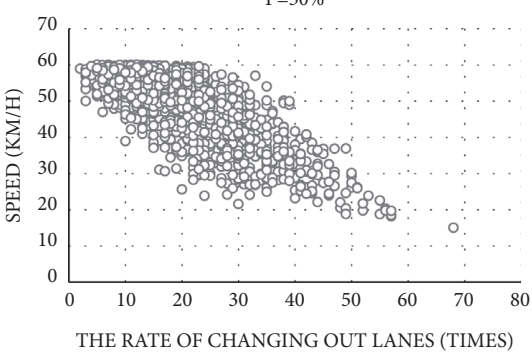

$\mathrm{P}=80 \%$

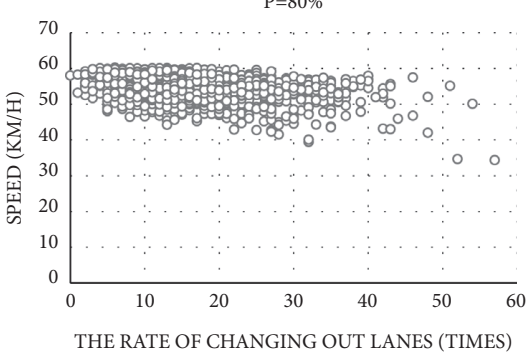

(b)

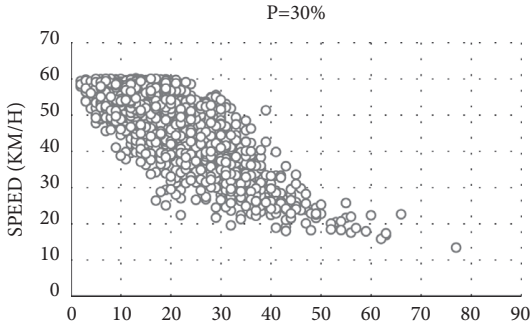

THE RATE OF CHANGING OUT LANES (TIMES)

$\mathrm{P}=60 \%$

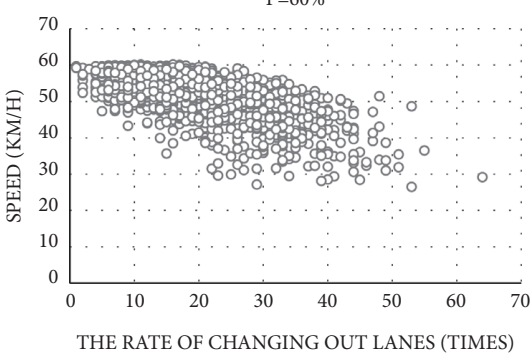

$\mathrm{P}=90 \%$

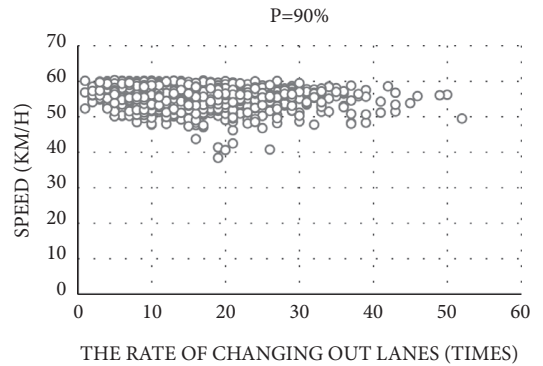

Figure 8: Continued. 

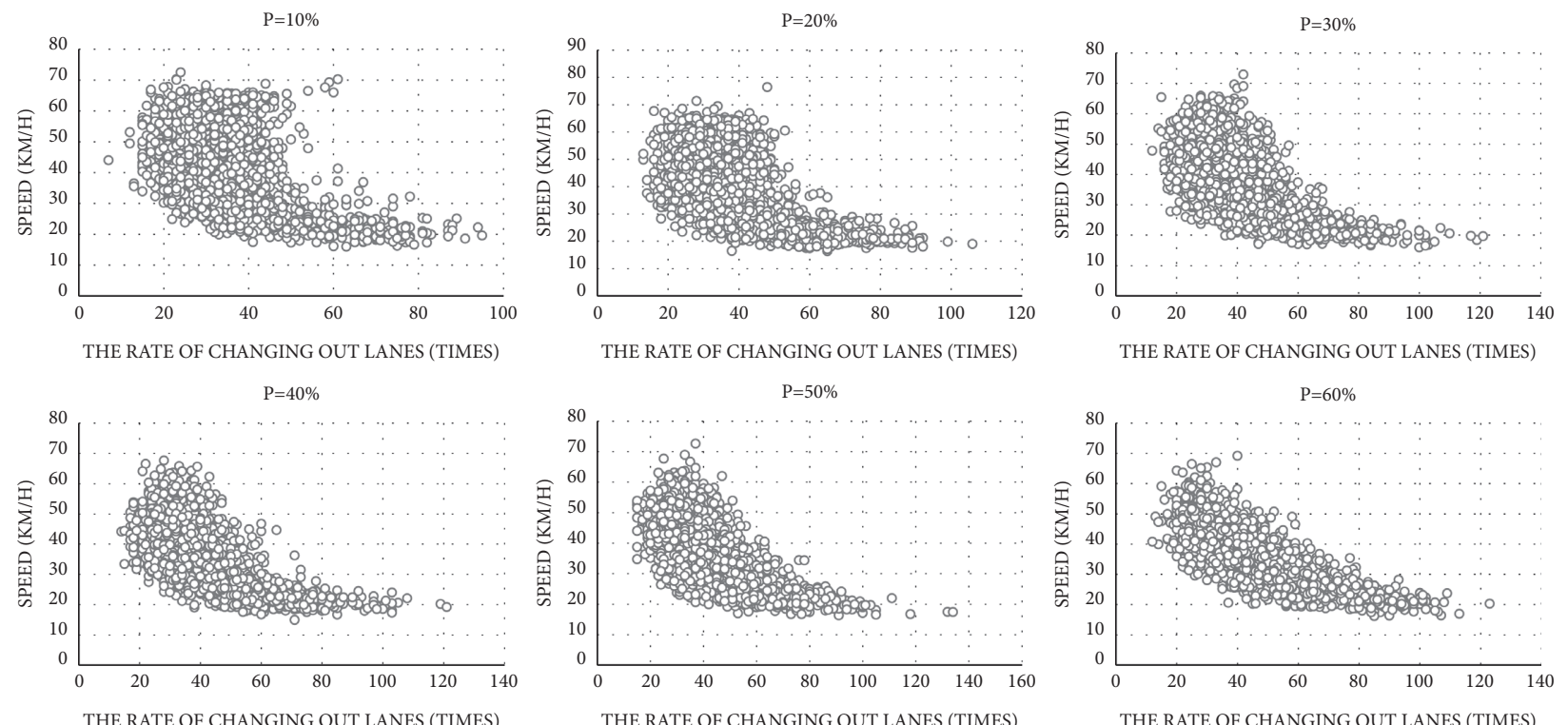

$\mathrm{P}=70 \%$
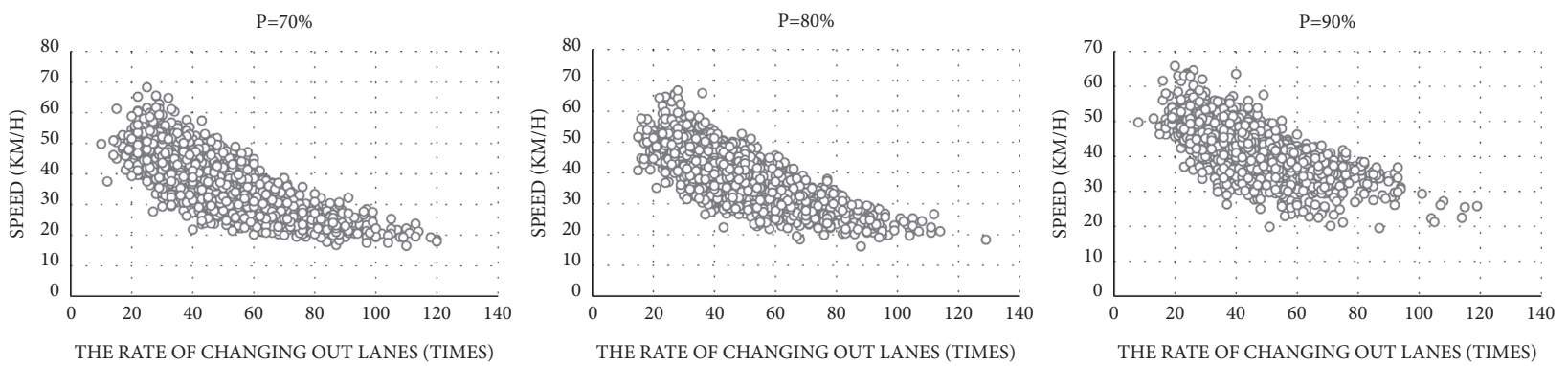

(c)

Figure 8: Continued. 


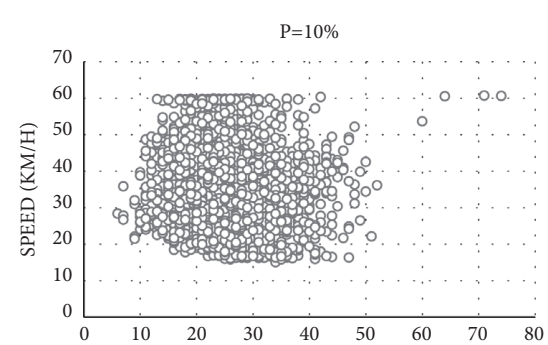

THE RATE OF CHANGING OUT LANES (TIMES)
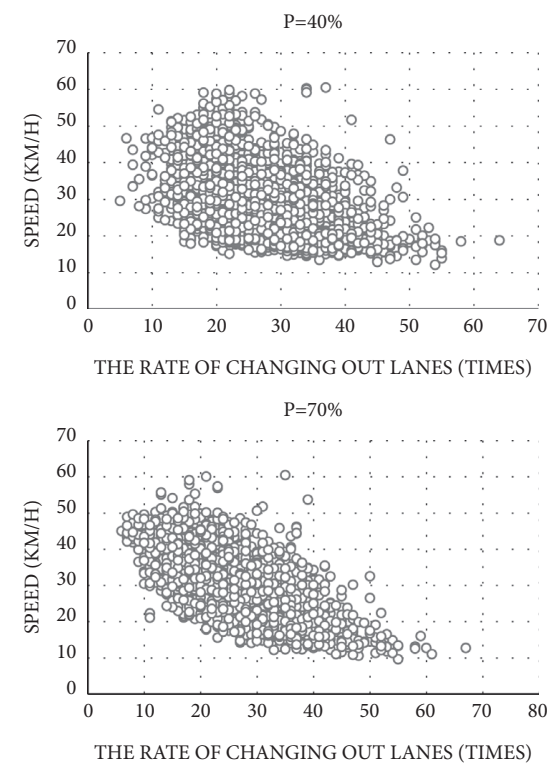
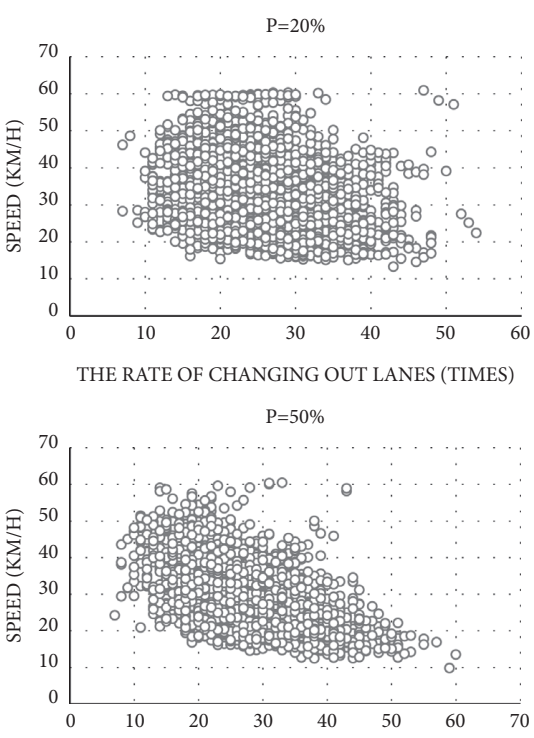

THE RATE OF CHANGING OUT LANES (TIMES)

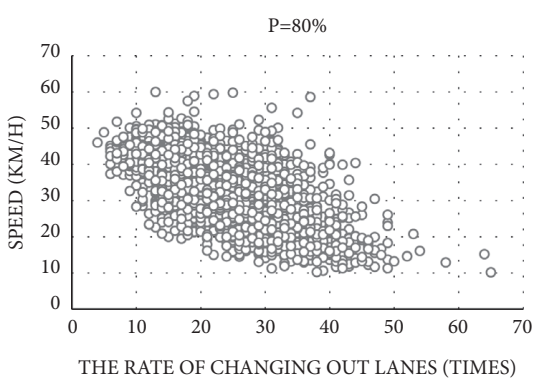

(d)
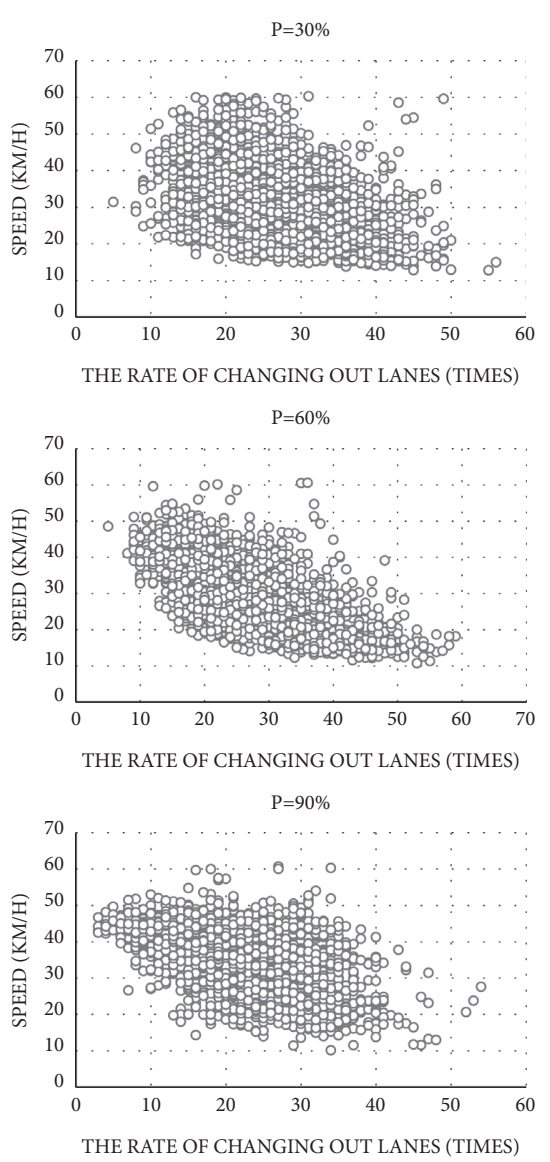

Figure 8: Scatter plot of the relationship between speed and the rate of changing out of lanes. (a) A scatter plot of Lane 1. (b) A scatter plot of Lane 2. (c) A scatter plot of Lane 3. (d) A scatter plot of Lane 4.

the relationship between speed and lane change rate. Since autonomous vehicles have different effects on the speed in each lane, the relationships between the speed and the lane change rate under different autonomous vehicles penetration rates need further analysis.

To verify there is a linear correlation between the speed and the lane change rate, the correlation analysis between the speed and the lane change rate in each lane under the different penetration rates of autonomous vehicles is shown in Table 5.

In Table 5, with the increase in the penetration rates of autonomous vehicles, the correlation in the speed and the rate of changing out of lanes, and the correlation in the speed and the rate of changing into lanes in Lane 1 and Lane 2 decrease, and the correlations in Lane 3 and Lane 4 enhanced. The relationship between speed and the rate of changing into lanes, and the relationship between speed and the rate of changing out of lanes can be observed from the scatter plot of the relationships, as shown in Figures 8 and 9 .

In Figures 8 and9, with the increase in the penetration rates of autonomous vehicles, the relationship between speed and the rate of changing out of lanes, and the relationship between speed and the rate of changing into lanes are closer in the same lane, but the relationships in different lanes are shown slightly different in the shape. Combined with Table 5, the relationships in Lane 1 and Lane 2 show a higher level of linearity when the penetration rate of autonomous vehicles is $10 \%$, and the relationships in Lane 3 and Lane 4 show a higher level of linearity when the penetration rate of autonomous vehicles is $80 \%$. For Lane 3 and Lane 4 , with the increase in the penetration rates of autonomous vehicles, the speed eventually decreases. According to the analysis of data distribution in Part 2 of this study, the speed, the rate of changing out of lanes, and the rate of changing into lanes present a partial normal distribution. Considering the analysis of the relationship between the speed and the rate of changing out of lanes, and the relationship between the speed and the rate of changing into lanes in Part 3 of this study, there are certain linear correlations between the speed and lane change rate. So regression analysis can be used to analyze the relationship between speed and lane change behavior.

3.2. Speed-Lane Change Rate Regression Model. In Figures 8, 9, and Table 5, there is a certain linear relationship between the speed $\mathrm{V}$ and the lane change rate. Regression analysis can be used to describe the relationship. 
TABLE 5: The linear correlation table between V, LCi, and LCo.

\begin{tabular}{|c|c|c|c|c|c|c|c|c|c|}
\hline & & \multicolumn{2}{|c|}{ Lane1 } & \multicolumn{2}{|c|}{ Lane2 } & \multicolumn{2}{|c|}{ Lane3 } & \multicolumn{2}{|c|}{ Lane4 } \\
\hline & & LCo & LCi & LCo & LCi & LCo & $\mathrm{LCi}$ & LCo & $\mathrm{LCi}$ \\
\hline$p=10 \%$ & $\begin{array}{l}\text { Pearson's Correlation } \\
\text { Sig. (2-tailed) }\end{array}$ & $\begin{array}{c}-0.508^{* *} \\
0\end{array}$ & $\begin{array}{c}-0.767^{* *} \\
0\end{array}$ & $\begin{array}{c}-0.701 \\
0\end{array}$ & $\begin{array}{c}-0.788^{* *} \\
0\end{array}$ & $\begin{array}{c}-0.512^{* *} \\
0\end{array}$ & $\begin{array}{c}-0.135^{* *} \\
0\end{array}$ & $\begin{array}{c}-0.093^{* *} \\
0\end{array}$ & $\begin{array}{c}-0.042^{*} \\
0.033\end{array}$ \\
\hline$p=20 \%$ & $\begin{array}{l}\text { Pearson's Correlation } \\
\text { Sig. (2-tailed) }\end{array}$ & $\begin{array}{c}-0.505^{* *} \\
0\end{array}$ & $\begin{array}{c}-0.735^{* *} \\
0\end{array}$ & $\begin{array}{c}-0.759^{* *} \\
0\end{array}$ & $\begin{array}{c}-0.762^{* *} \\
0 \\
\end{array}$ & $\begin{array}{c}-0.590^{* *} \\
0\end{array}$ & $\begin{array}{c}-0.295^{* *} \\
0 \\
\end{array}$ & $\begin{array}{c}-0.266^{* *} \\
0\end{array}$ & $\begin{array}{c}-0.309^{* *} \\
0\end{array}$ \\
\hline$p=30 \%$ & $\begin{array}{c}\text { Pearson's Correlation } \\
\text { Sig. (2-tailed) }\end{array}$ & $\begin{array}{c}-0.562^{* *} \\
0 \\
\end{array}$ & $\begin{array}{c}-0.760^{* *} \\
0 \\
\end{array}$ & $\begin{array}{c}-0.789^{* *} \\
0\end{array}$ & $\begin{array}{c}-0.769^{* *} \\
0 \\
\end{array}$ & $\begin{array}{c}-0.637^{* *} \\
0 \\
\end{array}$ & $\begin{array}{c}-0.431^{* *} \\
0\end{array}$ & $\begin{array}{c}-0.397^{* *} \\
0 \\
\end{array}$ & $\begin{array}{c}-0.478^{* *} \\
0 \\
\end{array}$ \\
\hline$p=40 \%$ & $\begin{array}{l}\text { Pearson's Correlation } \\
\text { Sig. (2-tailed) }\end{array}$ & $\begin{array}{c}-0.528^{* *} \\
0\end{array}$ & $\begin{array}{c}-0.750^{* *} \\
0\end{array}$ & $\begin{array}{c}-0.776^{* *} \\
0\end{array}$ & $\begin{array}{c}-0.759^{* *} \\
0\end{array}$ & $\begin{array}{c}-0.665^{* *} \\
0\end{array}$ & $\begin{array}{c}-0.470^{* *} \\
0\end{array}$ & $\begin{array}{c}-0.467^{* *} \\
9.16 E-141\end{array}$ & $\begin{array}{c}-0.518^{* *} \\
3.80 E-178\end{array}$ \\
\hline & $\begin{array}{l}\text { Pearson's Correlation } \\
\text { Sig. (2-tailed) }\end{array}$ & $\begin{array}{c}-0.549^{* *} \\
0\end{array}$ & $\begin{array}{c}-0.736^{* *} \\
0\end{array}$ & $\begin{array}{c}-0.770^{* *} \\
0\end{array}$ & $\begin{array}{c}-0.732^{* *} \\
0\end{array}$ & $\begin{array}{c}-0.692^{* *} \\
0\end{array}$ & $\begin{array}{c}-0.576^{* *} \\
0\end{array}$ & $\begin{array}{c}-0.542^{* *} \\
0\end{array}$ & $\begin{array}{c}-0.576^{* *} \\
0\end{array}$ \\
\hline & $\begin{array}{l}\text { Pearson's Correlation } \\
\text { Sig. (2-tailed) }\end{array}$ & $\begin{array}{c}-0.500^{* *} \\
0\end{array}$ & $\begin{array}{c}-0.617^{* *} \\
0\end{array}$ & $\begin{array}{c}-0.640^{* *} \\
0\end{array}$ & $\begin{array}{c}-0.593^{* *} \\
0\end{array}$ & $\begin{array}{c}-0.757^{* *} \\
0\end{array}$ & $\begin{array}{c}-0.665^{* *} \\
0\end{array}$ & $\begin{array}{c}-0.632^{* *} \\
2.72 E-28\end{array}$ & $\begin{array}{c}-0.707^{* *} \\
0\end{array}$ \\
\hline$p=70 \%$ & $\begin{array}{l}\text { Pearson's Correlation } \\
\text { Sig. (2-tailed) }\end{array}$ & $\begin{array}{c}-0.423^{* *} \\
0 \\
\end{array}$ & $\begin{array}{c}-0.531^{* *} \\
0 \\
\end{array}$ & $\begin{array}{c}-0.502^{* *} \\
0 \\
\end{array}$ & $\begin{array}{c}-0.482^{* *} \\
0 \\
\end{array}$ & $\begin{array}{c}-.788^{* *} \\
0 \\
\end{array}$ & $\begin{array}{c}-.694^{* *} \\
0 \\
\end{array}$ & $\begin{array}{c}-0.673^{* *} \\
0 \\
\end{array}$ & $\begin{array}{c}-0.762^{* *} \\
0 \\
\end{array}$ \\
\hline$p=80 \%$ & $\begin{array}{l}\text { Pearson's Correlation } \\
\text { Sig. (2-tailed) }\end{array}$ & $\begin{array}{c}-0.328^{* *} \\
0\end{array}$ & $\begin{array}{c}-0.401^{* *} \\
0\end{array}$ & $\begin{array}{c}-0.324^{* *} \\
0\end{array}$ & $\begin{array}{c}-0.341^{* *} \\
0\end{array}$ & $\begin{array}{c}-0.792^{* *} \\
0\end{array}$ & $\begin{array}{c}-0.682^{* *} \\
0\end{array}$ & $\begin{array}{c}-0.655^{* *} \\
0\end{array}$ & $\begin{array}{c}-0.776^{* *} \\
0\end{array}$ \\
\hline$p=90 \%$ & $\begin{array}{l}\text { Pearson's Correlation } \\
\text { Sig. (2-tailed) }\end{array}$ & $\begin{array}{c}-0.277^{* *} \\
0\end{array}$ & $\begin{array}{c}-0.319^{* *} \\
0\end{array}$ & $\begin{array}{c}-0.169^{* *} \\
0\end{array}$ & $\begin{array}{c}-0.194^{* *} \\
0\end{array}$ & $\begin{array}{c}-0.712^{* *} \\
0\end{array}$ & $\begin{array}{c}-0.540^{* *} \\
0\end{array}$ & $\begin{array}{c}-0.540^{* *} \\
0\end{array}$ & $\begin{array}{c}-0.719^{* *} \\
0\end{array}$ \\
\hline
\end{tabular}

Note: $(a)^{*}$ when 0.05 , significant correlation. $(b)^{* *}$ When 0.01 , significant correlation.

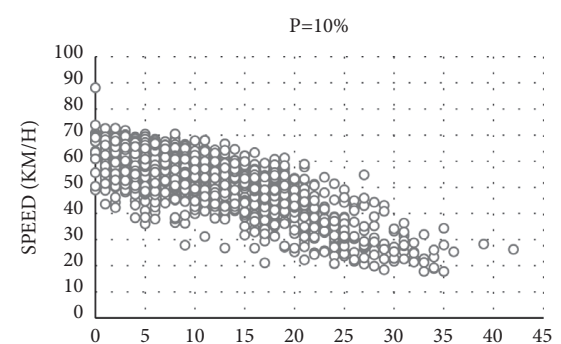

THE RATE OF CHANGING INTO LANES (TIMES)

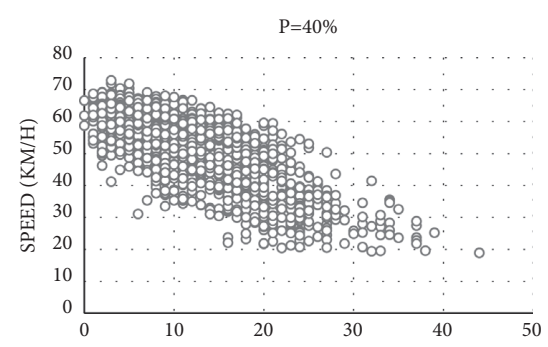

THE RATE OF CHANGING INTO LANES (TIMES)

$\mathrm{P}=70 \%$

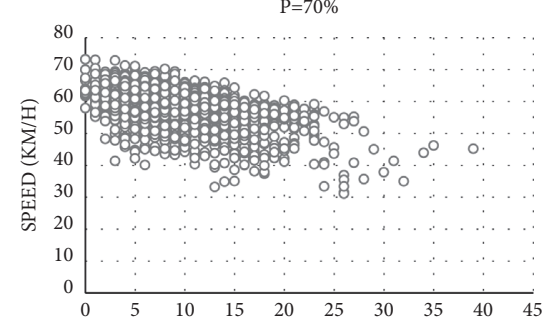

THE RATE OF CHANGING INTO LANES (TIMES)

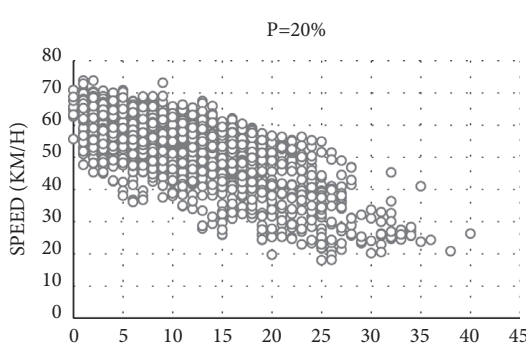

THE RATE OF CHANGING INTO LANES (TIMES)

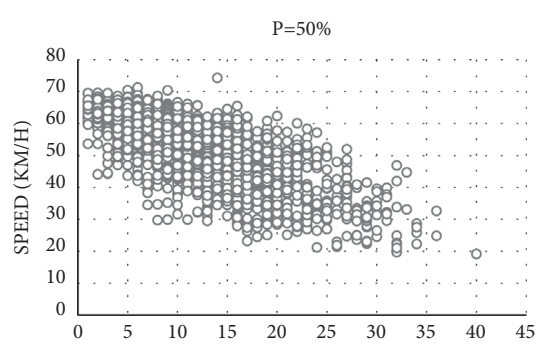

THE RATE OF CHANGING INTO LANES (TIMES)

$\mathrm{P}=80 \%$

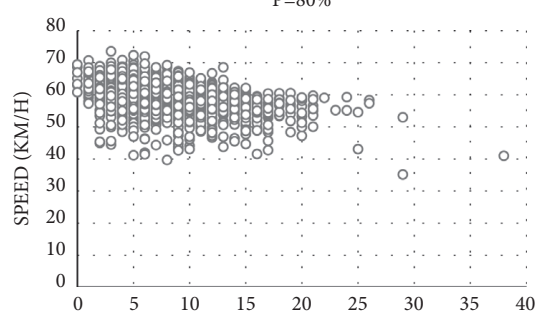

THE RATE OF CHANGING INTO LANES (TIMES)

(a)

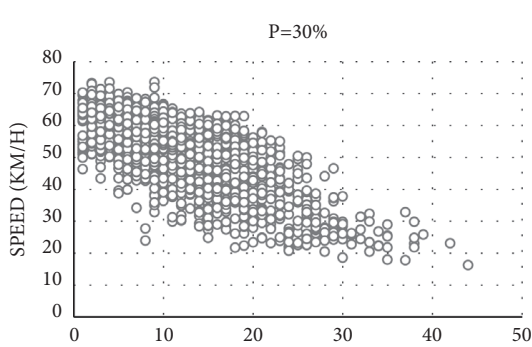

THE RATE OF CHANGING INTO LANES (TIMES)

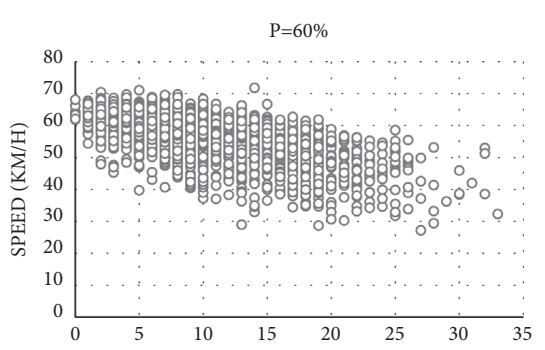

THE RATE OF CHANGING INTO LANES (TIMES)

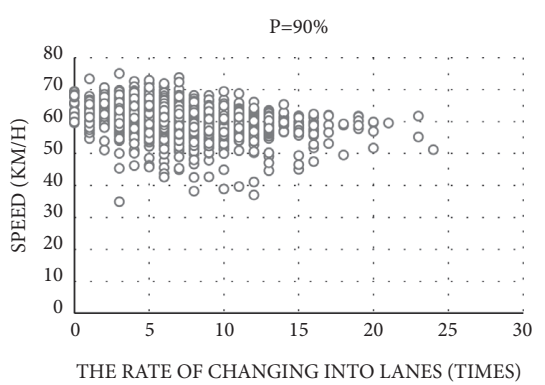

FIgURE 9: Continued. 

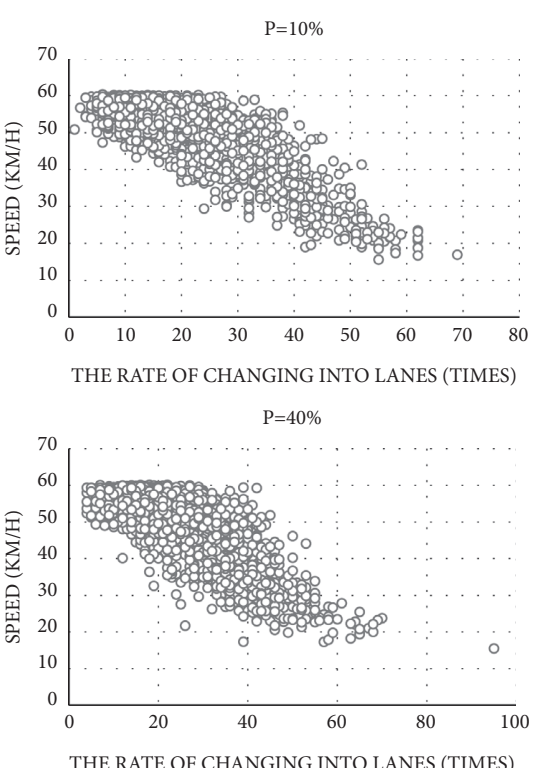

$\mathrm{P}=70 \%$

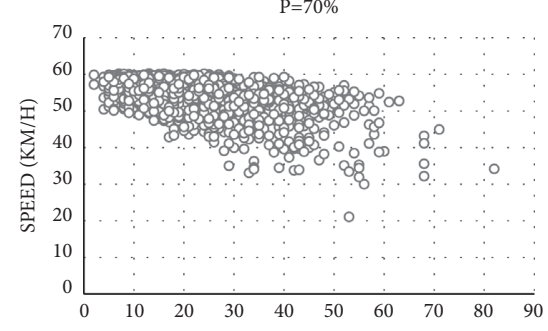

THE RATE OF CHANGING INTO LANES (TIMES)
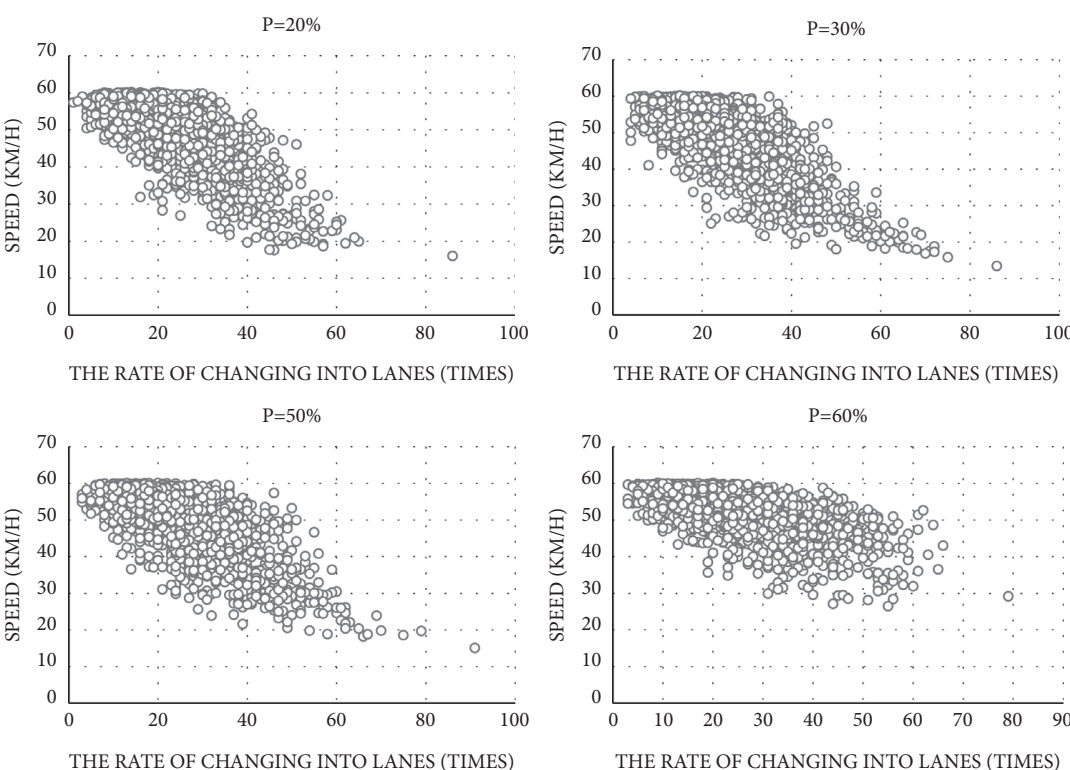

$\mathrm{P}=80 \%$

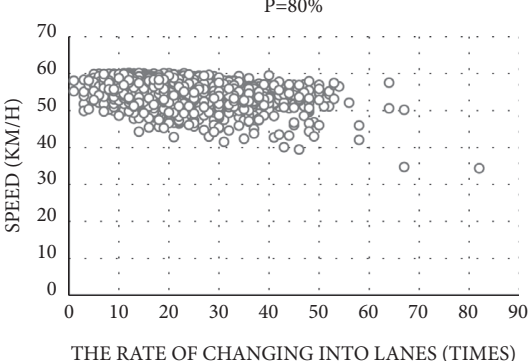

(b)

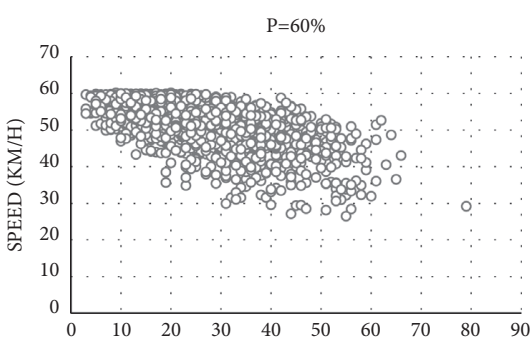

THE RATE OF CHANGING INTO LANES (TIMES)

$\mathrm{P}=90 \%$

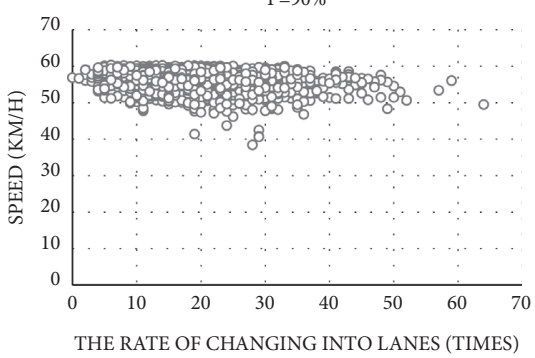

Figure 9: Continued. 


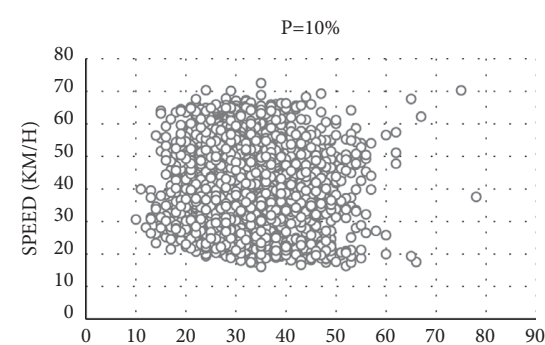

THE RATE OF CHANGING INTO LANES (TIMES)
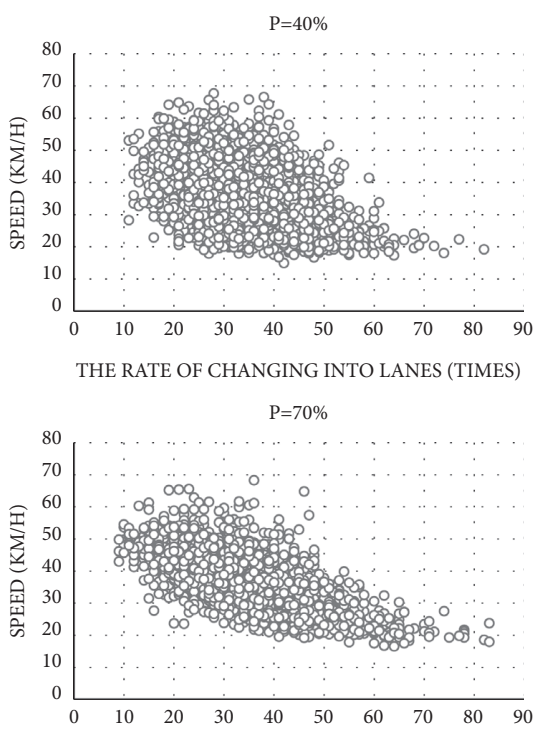

THE RATE OF CHANGING INTO LANES (TIMES)

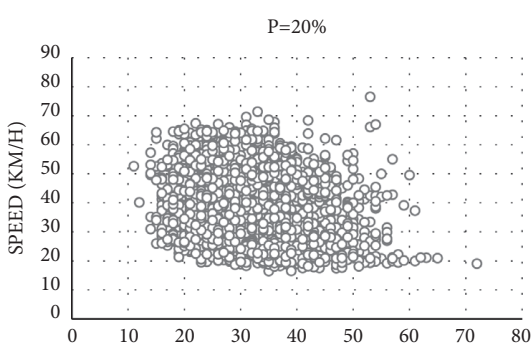

THE RATE OF CHANGING INTO LANES (TIMES)

$\mathrm{P}=50 \%$

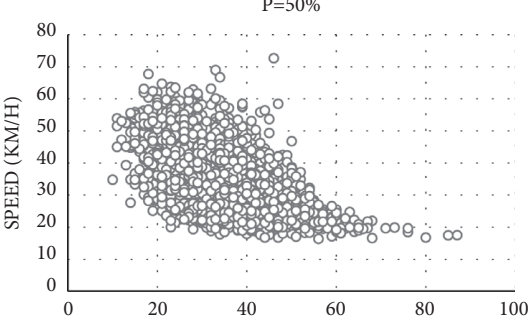

THE RATE OF CHANGING INTO LANES (TIMES)

$\mathrm{P}=80 \%$

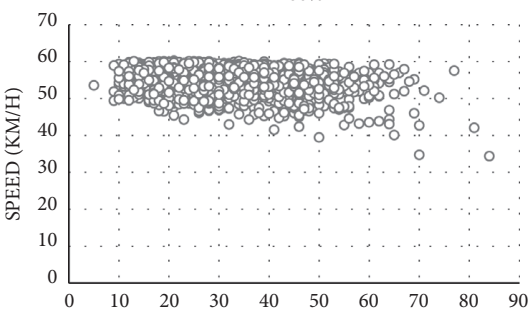

THE RATE OF CHANGING INTO LANES (TIMES)

(c)

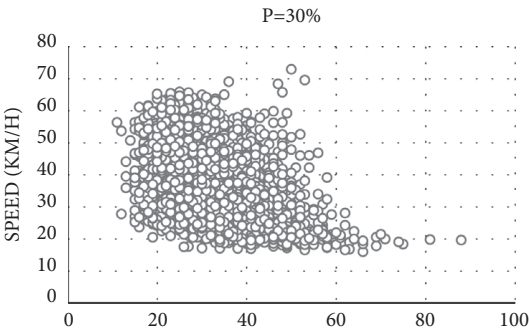

THE RATE OF CHANGING INTO LANES (TIMES)

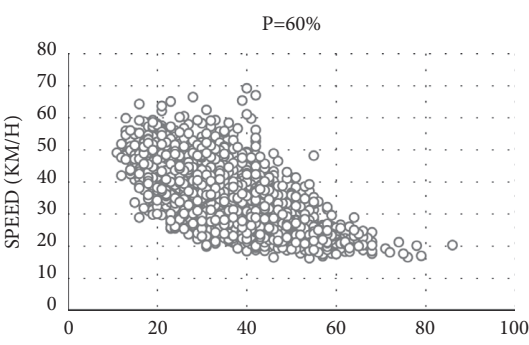

THE RATE OF CHANGING INTO LANES (TIMES)

$\mathrm{P}=90 \%$

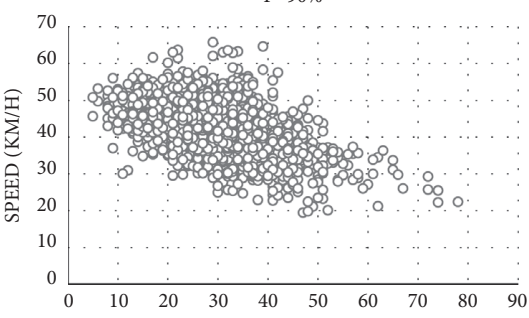

THE RATE OF CHANGING INTO LANES (TIMES)

FIgURE 9: Continued. 


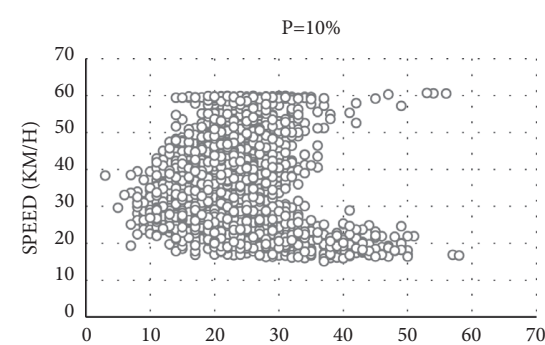

THE RATE OF CHANGING INTO LANES (TIMES)

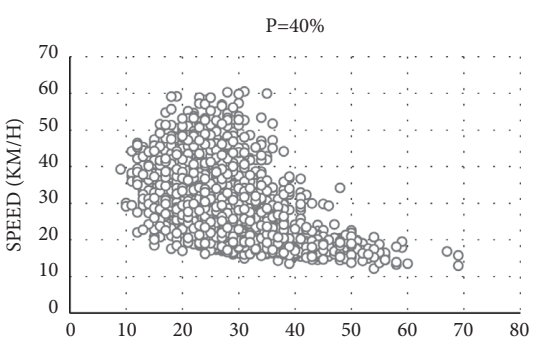

THE RATE OF CHANGING INTO LANES (TIMES) $\mathrm{P}=70 \%$

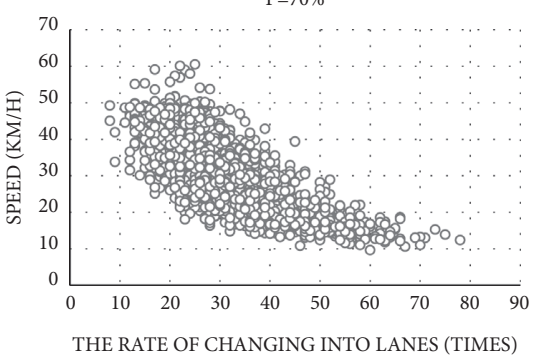

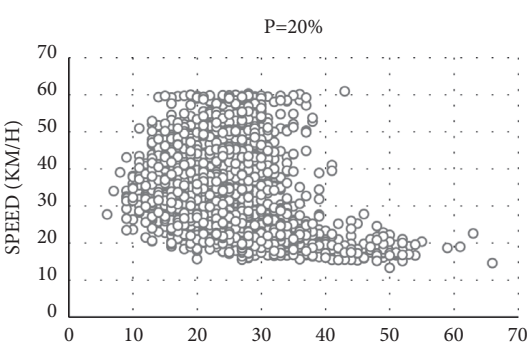

THE RATE OF CHANGING INTO LANES (TIMES)

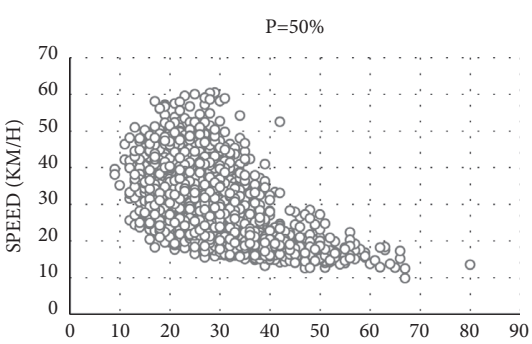

THE RATE OF CHANGING INTO LANES (TIMES)

$\mathrm{P}=80 \%$

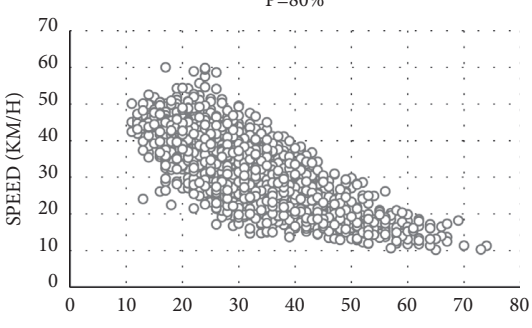

THE RATE OF CHANGING INTO LANES (TIMES)

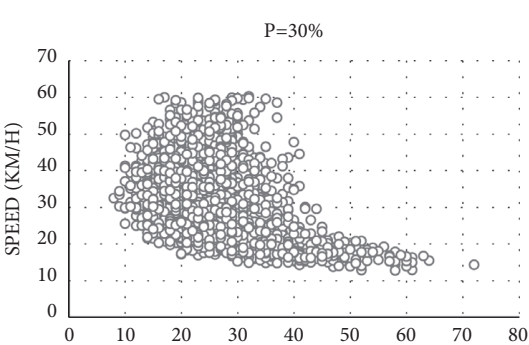

THE RATE OF CHANGING INTO LANES (TIMES)

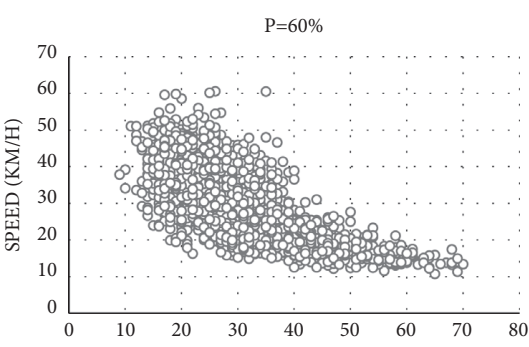

THE RATE OF CHANGING INTO LANES (TIMES)

$\mathrm{P}=90 \%$

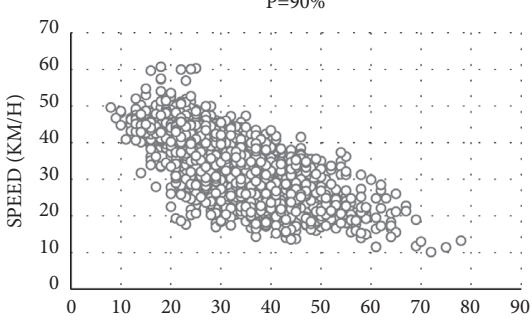

THE RATE OF CHANGING INTO LANES (TIMES)

(d)

Figure 9: Scatter plot of the relationship between speed and the rate of changing into lanes. (a) A scatter plot of Lane 1. (b) A scatter plot of Lane 2. (c) A scatter plot of Lane 3. (d) A scatter plot of Lane 4.

TABle 6: The degree of the fit table of the relationship between the speed and the lane change rate under different penetration rates of autonomous vehicles in each lane.

\begin{tabular}{ccccccccccc}
\hline & & $p=10 \%$ & $p=20 \%$ & $p=30 \%$ & $p=40 \%$ & $p=50 \%$ & $p=60 \%$ & $p=70 \%$ & $p=80 \%$ & $p=90 \%$ \\
\hline \multirow{4}{*}{ Lane1 } & Multiple $R$ & 0.777 & 0.837 & 0.832 & 0.852 & 0.849 & 0.865 & 0.535 & 0.889 & 0.343 \\
& $R$ square & 0.604 & 0.702 & 0.693 & 0.726 & 0.721 & 0.749 & 0.286 & 0.791 & 0.118 \\
& Adjusted $R$ square & 0.604 & 0.701 & 0.692 & 0.725 & 0.720 & 0.749 & 0.286 & 0.791 & 0.117 \\
& Standard error & 6.10 & 30.54 & 30.49 & 28.96 & 29.29 & 28.81 & 4.49 & 27.33 & 3.62 \\
\hline \multirow{5}{*}{ Lane2 } & Multiple $R$ & 0.796 & 0.837 & 0.798 & 0.846 & 0.774 & 0.878 & 0.511 & 0.904 & 0.202 \\
& $R$ square & 0.633 & 0.702 & 0.636 & 0.716 & 0.599 & 0.771 & 0.261 & 0.817 & 0.041 \\
& Adjusted $R$ square & 0.633 & 0.701 & 0.636 & 0.715 & 0.599 & 0.779 & 0.260 & 0.817 & 0.040 \\
& Standard error & 4.96 & 27.96 & 5.41 & 27.18 & 5.13 & 25.46 & 3.48 & 23.58 & 2.40 \\
\hline \multirow{4}{*}{ Lane3 } & Multiple $R$ & 0.512 & 0.899 & 0.645 & 0.884 & 0.712 & 0.872 & 0.800 & 0.885 & 0.716 \\
& $R$ square & 0.262 & 0.809 & 0.416 & 0.782 & 0.508 & 0.761 & 0.640 & 0.783 & 0.513 \\
& Adjusted $R$ square & 0.261 & 0.809 & 0.415 & 0.782 & 0.507 & 0.761 & 0.640 & 0.783 & 0.512 \\
& Standard error & 11.19 & 18.22 & 8.61 & 17.31 & 7.29 & 17.98 & 5.25 & 19.07 & 4.40 \\
\hline \multirow{2}{*}{ Lane4 } & Multiple $R$ & 0.097 & 0.899 & 0.538 & 0.878 & 0.663 & 0.850 & 0.805 & 0.851 & 0.753 \\
& $R$ square & 0.009 & 0.809 & 0.290 & 0.772 & 0.439 & 0.723 & 0.648 & 0.725 & 0.568 \\
& Adjusted $R$ square & 0.008 & 0.809 & 0.289 & 0.772 & 0.439 & 0.723 & 0.648 & 0.724 & 0.568 \\
& Standard error & 11.47 & 15.47 & 8.49 & 15.06 & 7.21 & 16.04 & 5.77 & 17.97 & 5.51 \\
\hline
\end{tabular}


TABLE 7: The parameter value interval table of the regression equation under different penetration rates of autonomous vehicles.

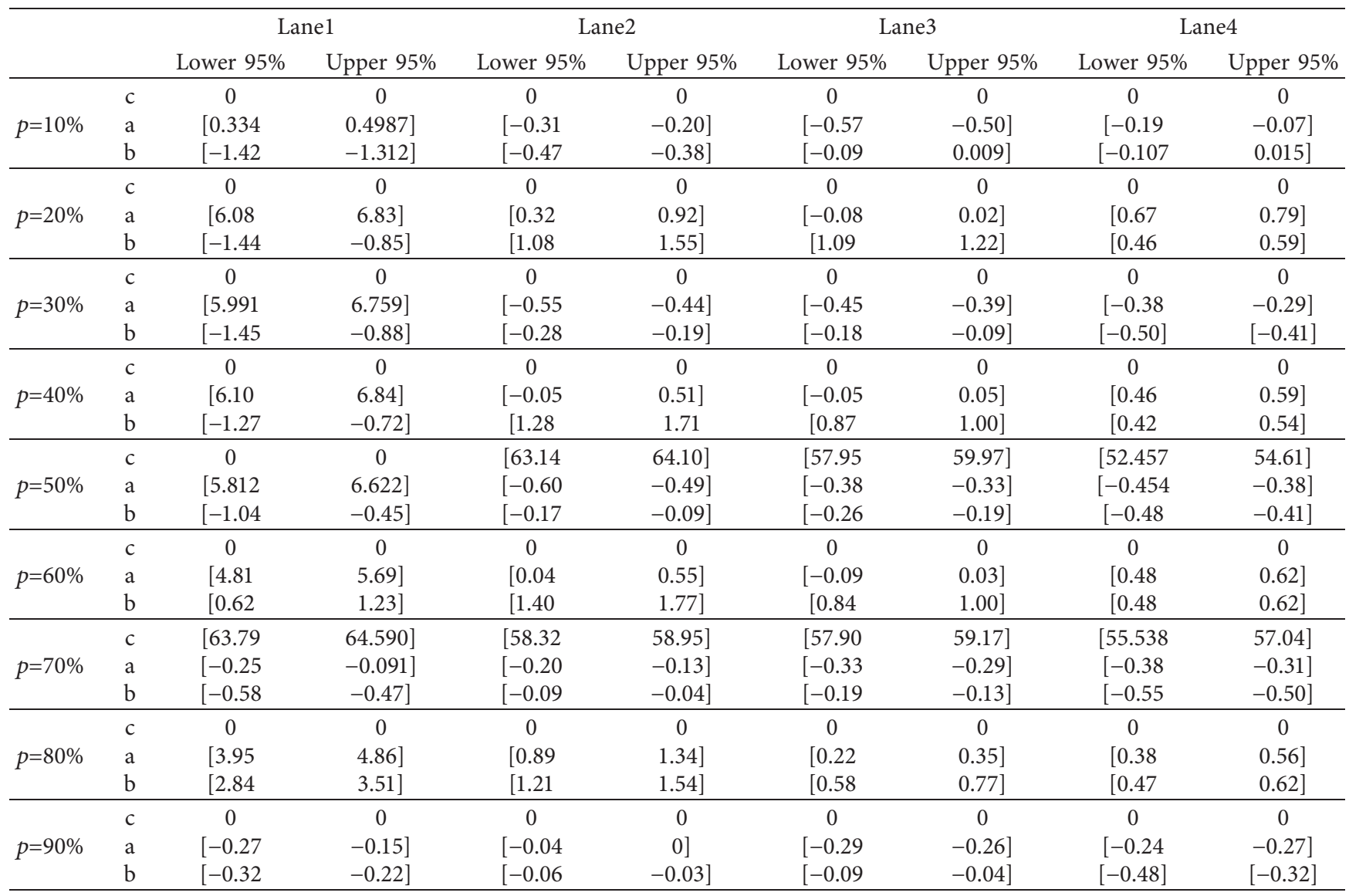

Assuming that there is a relationship between the speed $\mathrm{V}$, the rate of changing out of lanes LCo, and the rate of changing into lanes LCi, it can be expressed by the following formula:

$$
V=f(L C o, L C i)
$$

It is assumed that the relationship between the speed $\mathrm{V}$, the rate of changing out of lanes LCo, and the rate of changing into lanes LCi is expressed as a multivariate linear relationship, as shown in

$$
V=a L C o+b L C i+c .
$$

In the formula, $a, b$, and $c$ all represent constants.

Regression analysis is performed on the relationship between speed and lane change rate under different penetration rates of autonomous vehicles, and the degree of fit is shown in Table 6.

In Table 6 , the degree of fit $R$ is above 0.7 for each penetration rate in each lane, indicating that the relationship between speed and lane change rate is a linear relationship in mixed traffic. It means that the relationship between speed and lane change rate can be described by a linear relationship in mixed traffic, when the penetration rates of autonomous vehicles are greater than $10 \%$. The parameter value interval of Equation (7) under different penetration rates is shown in Table 7.

In Table 7, parameter $c$ obtained in all lanes with different penetration rates is all 0 . Parameter a shows an upward trend in Lane 1, and it also shows rise and fall trends in the other lanes. Parameter $b$ shows a downward trend in Lane 1, and it has the same trend in the other lanes, which is like parameter a. However, there is a slight change in trends of the parameters. All of those mean that formula (7) shows certain stability on the road in mixed traffic.

\section{Conclusions}

In this study, empirical and simulation methods are used to study the 4-lane urban expressway with typical ring road characteristics. When autonomous vehicles running on the road in a certain proportion, the speed of each lane on the road section is related to the lane-changing behavior in large traffic flow. In the empirical stage, video data, which are collected from 9 road sections on the third ring road in Chengdu, China, were used as the basis for establishing the simulation model. In the simulation model, the third ring road in Chengdu, China, was used as the benchmark object, and a simulation model of a 45 kilometer ring road with 9 exits and 36 entrances was established. In the model, the speed limit is also set according to the maximum speed limit of the third ring expressway of Chengdu. In order to further study the relationship between speed and lane change rate, only the large traffic flow was simulated. We simulated the situations under the penetration rates of autonomous vehicles of $10 \%, 20 \%, 30 \%, 40 \%, 50 \%, 60 \%, 70 \%, 80 \%$, and 
$90 \%$, respectively. We analyzed the data of the speed, the rate of changing out of lanes, and the rate of changing into lanes in each lane. Then, we found that

(1) Speed in each lane is affected by autonomous vehicles running on the road to a certain extent. The speed of the two lanes, which are far away from the entrance and exit, shows a downward trend when the penetration rates of autonomous vehicles are $10 \%$ and $30 \%$. But with the increase in the penetration rates of autonomous vehicles, the speed is effectively increased. The speed of the two lanes, which are close to the entrance and exit, shows a downward trend with the increase in autonomous vehicle penetration rates, especially the lane that is directly connected with the entrance or exit.

(2) The rate of changing out of lanes and the rate of changing into lanes are closer to the changes in each lane with different penetration rates of autonomous vehicles. When the penetration rate of autonomous vehicles is $10 \%$, the rate of changing into lanes and the rate of changing out of lanes have relatively obvious downward trends from Lane 1 to Lane 3 and have no obvious trend in Lane 4 . Then, with the increase in the penetration rates of autonomous vehicles, the rate of changing into lanes and the rate of changing out of lanes did not significantly change.

(3) With the penetration of autonomous vehicles, the speed, the rate of changing out of lanes, and the rate of changing into lanes in all lanes show tendencies to converge toward the mode position. Compared with $0 \%$ penetration rate of autonomous vehicles, the autonomous vehicles take the behavior of changing lanes more balanced in the whole time.

(4) With the penetration of autonomous vehicles, there is a linear relationship between speed, the rate of changing out of lanes, and the rate of changing into lanes. Although the data representations of the three factors are still non-normally distributed, the fit degree obtained after regression analysis remains above 0.7 under different penetration rates of autonomous vehicles in different lanes. Those mean that a linear relationship between speed and lane change rate exists in the mixed traffic.

In conclusion, we believe that in the 4-lane urban expressway with large traffic flow, autonomous vehicles have a certain effect on improving traffic flow. With the penetration of autonomous vehicles, the speed is significantly increased in the lane far away from the entrance and exit, but it is not obvious or even shows a slight downward trend for the lane closer to the entrance and exit. However, the lane-changing behavior only is decreased to a certain extent when the penetration rate is $10 \%$. As the penetration rate increases, the decreasing trend is not obvious. The speed and lane change rate show a linear relationship. Under different penetration rates, its parameters do not change much, and the formula has a certain stability.
In addition, this study also has some shortcomings. The speed-lane change rate model proposed in this study has not been tested for its applicability in mixed traffic on other roads. These are the directions for further research studies in the future.

\section{Data Availability}

The data used in this research can be found via the corresponding author.

\section{Conflicts of Interest}

The authors declare that there are no conflicts of interest regarding the publication of this paper.

\section{Acknowledgments}

This research was supported by the Applied Basic Research Programs and Technology Commission Foundation of Sichuan Province of China (Grant Nos. 2019JDR0093, 2020JDR0253, 2021YJ0066, 2017JY0246, and 2017JY0269), the Chengdu Science and Technology Project (Grant Nos. 2017RK0000306ZF and 2017RK0000357ZF), and the Key Scientific Research Fund of Xihua University (Grant No. Z17131). The authors would like to thank Dr. Qinhua Ren, Dr. Juanxiu Zhu, Dr. Huawei Duan, Dr. Kehong Li, and Mr. Zheng Lei for their contribution to data collection and analysis and preparation of the manuscript. The authors would also like to thank their school brothers and school sisters for their support and help in the process of research and writing.

\section{References}

[1] G. Orosz, R. E. Wilson, and G. Stépán, "Traffic jams: dynamics and control," Philosophical Transactions of the Royal Society A: Mathematical, Physical \& Engineering Sciences, vol. 368, no. 1928, pp. 4455-4479, 2010.

[2] D. Ngoduy, "Analytical studies on the instabilities of heterogeneous intelligent traffic flow," Communications in Nonlinear Science and Numerical Simulation, vol. 18, no. 10, pp. 2699-2706, 2013.

[3] J. Sun, Z. Zheng, and J. Sun, "Stability analysis methods and their applicability to car-following models in conventional and connected environments," Transportation Research Part B: Methodological, vol. 109, pp. 212-237, 2018.

[4] C. Wang, Q. Sun, Z. Li, H. Zhang, and K. Ruan, "Cognitive competence improvement for autonomous vehicles: a lane change identification model for distant preceding vehicles," IEEE Access, vol. 7, pp. 83229-83242, 2019.

[5] Y. S. Jiang, R. Hu, Z. H. Yao, P. C. Wu, and X. L. Luo, "Stability and safety analysis for heterogeneous traffic flow composed of intelligent and connected vehicles," Journal of Veijing Jiaotong University, vol. 44, no. 01, pp. 27-33, 2020.

[6] L. Huang, H. Guo, R. Zhang, H. Wang, and J. Wu, "Capturing drivers' lane changing behaviors on operational level by data driven methods," IEEE Access, vol. 6, pp. 57497-57506, 2018.

[7] H. Wang, Y. Qin, W. Wang, and J. Chen, "Stability of CACCmanual heterogeneous vehicular flow with partial CACC performance degrading," Transportation Business: Transport Dynamics.vol. 7, no. 1, pp. 1-26, 2019. 
[8] Y. Dou, Y. Fang, C. Hu, R. Zheng, and F. Yan, "Gated branch neural network for mandatory lane changing suggestion at the on-ramps of highway," IET Intelligent Transport Systems, vol. 13, no. 1, pp. 48-54, 2019.

[9] A. Kesting, M. Treiber, and D. Helbing, "Enhanced intelligent driver model to access the impact of driving strategies on traffic capacity," Philosophical Transactions of the Royal Society A: Mathematical, Physical \& Engineering Sciences, vol. 368, no. 1928, pp. 4585-4605, 2010.

[10] Y. Liu, J. Guo, J. Taplin, and Y. Wang, "Characteristic analysis of mixed traffic flow of regular and autonomous vehicles using cellular automata," Journal of Advanced Transportation, vol. 2017, pp. 1-10, Article ID 2854895, 2017.

[11] L. Ye and T. Yamamoto, "Impact of dedicated lanes for connected and autonomous vehicle on traffic flow throughput," Physica A: Statistical Mechanics and Its Applications, vol. 512, pp. 588-597, 2018.

[12] W. Li, S. Chen, X. Wang, C. Yin, and Z. Huang, "A hybrid approach for short-term traffic flow forecasting based on similarity identification," Modern Physics Letters B, vol. 35, no. 13, p. 2150212, 2021.

[13] S. Wang, J. Zhao, C. Shao, C. Dong, and C. Yin, "Truck traffic flow prediction based on LSTM and GRU methods with sampled GPS data," IEEE Access, vol. 8, pp. 208158-208169, 2020.

[14] A. Talebrour and H. S. Mahmassani, "Influence of connected and autonomous vehicles on traffic flow stability and throughput," Transportation Research Part C: Emerging Technologies, vol. 71, pp. 143-163, 2016.

[15] L. Ye and T. Yamamoto, "Modeling connected and autonomous vehicles in heterogeneous traffic flow," Physica A: Statistical Mechanics and Its Applications, vol. 490, pp. 269277, 2018.

[16] M. W. Levin and S. D. Boyles, "A multiclass cell transmission model for shared human and autonomous vehicle roads," Transportation Research Part C: Emerging Technologies, vol. 62, pp. 103-116, 2016.

[17] G. Li, Z. Yang, Q. Yu, J. Ma, and S. Fang, "Characterizing heterogeneity among merging positions: comparison study between random parameter and latent class Accelerated hazard model," Journal of Transportation Engineering, Part A: Systems, vol. 147, no. 6, p. 4021029, 2021.

[18] X. Wang, W. Li, C. Yin, S. Zeng, and P. Liu, "A multipleparameter approach for short-term traffic flow prediction," Modern Physics Letters B, vol. 35, no. 14, p. 2150245, 2021.

[19] Z. Yao, H. Jiang, Y. Cheng, Y. Jiang, and B. Ran, "Integrated schedule and trajectory optimization for connected automated vehicles in a conflict zone," IEEE Transactions on Intelligent Transportation Systems, pp. 1-11, 2020.

[20] Y. Y. Qin Yan-Yan, H. Wang Hao, W. Wang Wei, and Q. Wan Qian, "Stability analysis and fundamental diagram of heterogeneous traffic flow mixed with cooperative adaptive cruise control vehicles," Acta Physica Sinica, vol. 66, no. 9, p. 094502, 2017.

[21] Z. Yao, R. Hu, Y. Wang, Y. Jiang, B. Ran, and Y. Chen, "Stability analysis and the fundamental diagram for mixed connected automated and human-driven vehicles," Physica A: Statistical Mechanics and Its Applications, vol. 533, p. 121931, 2019.

[22] J. A. Laval and C. F. Daganzo, "A hybrid model of traffic flow: impacts of roadway geometry on capacity," in Proceedings of the TRB 2003 Annual Meeting CD-ROM, The Georgia Institute of Technology, Atlanta, Georgia, 2003.
[23] G. F. Newell, “A moving bottleneck," Transportation Research Part B: Methodological, vol. 32, no. 8, pp. 531-537, 1998.

[24] J. A. Laval and C. F. Daganzo, "Lane-changing in traffic streams," Transportation Research Part B: Methodological, vol. 40, no. 3, pp. 251-264, 2006.

[25] W.-L. Jin, "A kinematic wave theory of lane-changing traffic flow," Transportation Research Part B: Methodological, vol. 44, no. 8-9, pp. 1001-1021, 2010.

[26] Transportation Research Board, Highway Capacity Manual (HCM2010), National Academy of Sciences, USA, 2010.

[27] S. Park and S. G. Ritchie, "Exploring the relationship between freeway speed variance, lane changing and vehicle heterogeneity[R]," in Proceedings of the 83rd Annual Meeting of the Transportation Research Board, Washington D. C.UCI-ITSTS-WP-04-4, Washington D. C., 2004.

[28] F. Gmez -Bravo, F. Cuesta, A. Oliero, and A. Viguria, "Continuous curvature path generation based on $\beta$-spline curves for parking manoeuvres," Robotics and Autonomous Systems, vol. 56, no. 4, pp. 360-372, 2008.

[29] H. Sun, W. W. Deng, and S. M. Zhang, "Micro vehicle dynamic trajectory plan with global optimality," Journal of the University (Engineering and Technology Edition), vol. 44, no. 4, pp. 918-924, 2014.

[30] F. C. Lan, S. C. Li, J. Q. Chen, and Z. L. Liu, "Comprehensive approach for trajectory optimization of autopilot vehicles considering handling stability," Journal of Hunan University, vol. 46, no. 10, pp. 36-45, 2019.

[31] A. Kesting, M. Treiber, and D. Helbing, "General lanechanging model MOBIL for car-following models," Transportation Research Record: Journal of the Transportation Research Board, vol. 1999, no. 1, pp. 86-94, 2007.

[32] C. Vallon, Z. Ercan, A. Carvalho, and F. Borrelli, "A machine learning approach for personalized autonomous lane change initiation and control," in Proceedings of the 2017 IEEE Intelligent Vehicles Symposium(IV), pp. 1590-1595, IEEE, Los Angeles, CA, USA, June 2017.

[33] K. Liu, J. Gong, A. Kurt, H. Chen, and U. Ozguner, "Dynamic modeling and control of high-speed automated vehicles for lane change maneuver," IEEE TRANSACTIONS ON INTELLIGENT VEHICLES, vol. 3, no. 3, pp. 329-339, 2018.

[34] H. Zheng, J. Zhou, Q. Shao, and Y. Wang, "Investigation of a longitudinal and lateral lane-changing motion planning model for intelligent vehicles in dynamical driving environments," IEEE Access, vol. 7, pp. 44783-44802, 2019.

[35] S. Jongsang, C. Heungseok, and Y. Kyongsu, "Stochastic model-predictive control for lane change decision of automated driving vehicles," IEEE Transactions on Vehicular Technology, vol. 67, no. 6, pp. 4771-4782, 2018.

[36] Y. Ekim, Y. Suguru, M. Chiyomi et al., "Integrating driving behavior and traffic context through signal symbolization for data reduction and risky lane change detection," IEEE TRANSACTIONS ON INTELLIGENT VEHICLES, vol. 3, no. 3, pp. 242-253, 2018.

[37] Z. Wang, X. Zhao, Z. Xu, X. Li, and X. Qu, "Modeling and field experiments on autonomous vehicle lane changing with surrounding human-driven vehicles," Computer-Aided Civil and Infrastructure Engineering, vol. 36, no. 7, pp. 877-889, 2020.

[38] L. Seolyoung, O. Cheol, and H. Sungmin, "Exploring lane change safety issues for manually driven vehicles in vehicle platooning environments," IET Intelligent Transport Systems, vol. 12, no. 9, pp. 1142-1147, 2018. 
[39] P. Cao, Z. Xu, Q. Fan, and X. Liu, "Analysing driving efficiency of mandatory lane change decision for autonomous vehicles," IET Intelligent Transport Systems, vol. 13, no. 3, pp. 506-514, 2019.

[40] Ministry of Housing and Urban-Rural Development of the People's Republic of China.Design Discipline of Urban Expressway, pp. 1-5, China Architecture \& Building Press, Beijing, China, 2009.

[41] Q. S. Zhang and Y. P. Zhang, Analysis of Road Traffic Capacity, China communication press, Beijing, 2002. 